\title{
Sustainable distribution system design: a two-phase DoE-guided meta-heuristic solution approach for a three-echelon bi-objective AHP-integrated location-routing model
}

\author{
Sahar Validi $^{1}$ - Arijit Bhattacharya ${ }^{2}$. \\ P. J. Byrne ${ }^{3}$
}

Published online: 17 May 2018

(C) The Author(s) 2018

\begin{abstract}
This article introduces a sustainable integrated bi-objective location-routing model, its two-phase solution approach and an analysis procedure for the distribution side of three-echelon logistics networks. The mixed-integer programming model captures several real-world factors by introducing an additional objective function and a set of new constraints in the model that outbound logistics channels find difficult to reconcile. The sustainable model minimises $\mathrm{CO}_{2}$ emissions from transportation and total costs incurred in facilities and the transportation channels. Design of Experiment (DoE) is integrated to the meta-heuristic based optimiser to solve the model in two phases. The DoE-guided solution approach enables the optimiser to offer the best stable solution space by taking out solutions with poor design features from the space and refining the feasible solutions using a convergence algorithm thereby selecting the realistic results. Several alternative solution scenarios are obtained by prioritising and ranking the realistic solution sets through a multi-attribute decision analysis tool, Technique for Order Preference by Similarity to Ideal Solution (TOPSIS). The robust model provides the decision maker the ability to take decisions on sustainable open alternative optimal routes. The outcomes of this research provide theoretical and methodological contributions, in terms of integrated bi-objective location-routing model and its two-phase DoE-guided meta-heuristic solution approach, for the distribution side of three-echelon logistics networks.
\end{abstract}

Arijit Bhattacharya

A.Bhattacharya@uea.ac.uk; arijit.bhattacharya2005@gmail.com

Sahar Validi

S.Validi@hud.ac.uk

P. J. Byrne

pj.byrne@dcu.ie

1 Logistics Transport and Supply Chain Subject Group, School of Business, University of Huddersfield, Queensgate, Huddersfield HD1 3DH, UK

2 Norwich Business School, University of East Anglia, Norwich Research Park, Norwich NR4 7TJ, UK

3 Dublin City University Business School, Dublin City University, Glasnevin, Dublin 9, Ireland 
Keywords Sustainable logistics network - Location-routing - Bi-objective programming · Mixed-integer programming · Multi-attribute decision analysis · DoE-guided meta-heuristic solution

\section{Introduction}

Sustainable logistics operations and their effect on carbon emissions and costs are a current strategic challenge in modern supply chains (SCs) (Du et al. 2017; McKinnon et al. 2015; Brandenburg and Rebs 2015; Kumar et al. 2012; Srivastava 2007). Logistics activities have been identified as one of the most significant sources of air pollution and greenhouse gas emissions (Sheu and Li 2014; Wang et al. 2011). Efficient and effective design of the outbound logistic system is one of the critical success factors for sustainable movement of products to multiple retailers and consumers (Lopes et al. 2008). Therefore, sustainable location-routing problem (LRP) is of major concern in logistics networks design (Srivastava 2007; Seuring and Müller 2008).

A sustainable transportation strategy within a logistics network promotes an approach that seeks to achieve mutually reinforcing benefits for the economy, the environment and society (Ilbery and Maye 2005). The Paris Agreement (United Nations Treaty Collection 2017) sets out a global action plan to reduce member states' carbon emission through a legally binding global climate deal and encourages businesses to significantly reduce carbon emissions from their operations. Transportation activities on the demand side of the SC via roadways leave harmful effects on human health and the environment. Therefore, the transportation routes should be planned so as to minimise $\mathrm{CO}_{2}$ emissions and costs resulted from transportation activities.

Driven by the current laws and regulations and competitive business opportunities on the sustainable transportation mechanism, this article addresses three inter-linked aspects of sustainable location-routing. First a sustainable bi-objective three-echelon integrated optimisation model is proposed, next a Design of Experiment (DoE)-guided meta-heuristic-based robust solution approach is provided to solve the computationally NP-hard integrated model, and the Decision-Makers' (DMs') prioritisation and ranking of the realistic solution sets, and various routing scenarios of the three-echelon sustainable location-routing are illustrated.

The model addresses all three echelons on the distribution side of the logistics network responsible for carbon emission. The weighting procedures of Analytic Hierarchy Process (AHP) (Saaty 1994) is infused into the bi-objective 0-1 integer programming in order to provide flexibility in the vehicle selection decision-making process. The computational complexity of the NP-hard model necessitates the solution approach to divide the model into two inter-connected phases. While Phase-I deals with the sustainable transportation mechanism from the processing plants to the multiple distribution centres (DCs) and DCs to multiple retailers, Phase-II uses the outcome of Phase-I to locate the non-dominated Pareto realistic optimal routes among retailers. The DoE-guided Multiple-Objective Genetic Algorithm of kind II (MOGA-II) optimiser enables the model to obtain the best set of realistic solutions. Disparate scenarios of the realistic vehicle routes are captured with alternative possible outcomes from both the phases. The final set of optimal and realistic solutions is then obtained from the synergistic effect resulted from both phases. The best set of realistic sustainable optimal solutions is then obtained.

The remainder of this paper is organised as follows. Section 3 formulates the sustainable three-echelon location-routing model. The two-phase solution approach to the NP-hard 
Table 1 Applications of location-routing problems

\begin{tabular}{|c|c|}
\hline Publications & Applications \\
\hline Perl and Daskin $(1984,1985)$ & Goods distribution \\
\hline $\begin{array}{l}\text { Jacobsen and Madsen (1980), Madsen (1983), } \\
\text { Mantel and Fontein (1993) }\end{array}$ & Newspaper distribution \\
\hline Or and Pierskalla (1979) & Blood bank location \\
\hline Watson-Gandy and Dohrn (1973) & Food and drink distribution \\
\hline Labbé and Laporte (1986) & Post-box location \\
\hline Aksen and Altinkemer (2008) & Distribution logistics \\
\hline $\begin{array}{l}\text { Kulcar (1996), Caballero et al. (2007), Vidović et al. } \\
\text { (2016), Asgari et al. (2017) }\end{array}$ & Waste collection \\
\hline Chan et al. (2001) & Medical evacuation \\
\hline Alumur and Kara (2007), Chang et al. (2005) & $\begin{array}{l}\text { Collection, transportation, treatment and disposal of } \\
\text { hazardous material }\end{array}$ \\
\hline Cappanera et al. (2004), Stowers and Palekar (1993) & Obnoxious facility location-routing \\
\hline Murty and Djang (1999) & Military application \\
\hline Bruns et al. (2000), Wasner and Zäpfel (2004) & Parcel delivery \\
\hline Lin et al. (2002) & Bill delivery services \\
\hline Sbihi and Eglese (2010), Zhang and Zhao (2011) & Hazardous waste location-routing \\
\hline Stenger et al. (2012) & Small package shippers \\
\hline Gunnarsson et al. (2006) & Shipping industry \\
\hline Validi et al. (2012, 2014a, b, 2015) & $\begin{array}{l}\text { Perishable food product distribution (low-carbon } \\
\text { logistics) }\end{array}$ \\
\hline
\end{tabular}

model is explained in Sect. 4. Next section implements the model and its two-phase solution approach on a three-echelon dairy processing logistics network based in Ireland. The results and analysis of the implemented model are illustrated in Sect. 6. A critical discussion on the results is also included in this section. Finally, Sect. 7 concludes the paper with an implication of the proposed approach on sustainable location-routing on the demand side of logistics network.

\section{Theoretical background}

Literature on conventional LRPs is rich in terms of both methodologies and applications. Prominent reviews can be found in Madsen (1983), Nagy and Salhi (2007), Dekker et al. (2012), Demir et al. (2014), Prodhon and Prins (2014), Eskandarpour et al. (2015), Drexl and Schneider (2015), Vega-Mejía et al. (2017). The purpose of LRP methodologies is the simultaneous determination of the location of facilities and the routes of vehicles for product transportation (Laporte et al. 1988; Nagy and Salhi 2007; Yu et al. 2010). A broad range of LRP applications is found in the literature. A synopsis of these applications is illustrated in Table 1.

The nature of the LRP problems stimulates practitioners to use a range of optimisation techniques. Stochastic (Laporte et al. 1989; Albareda-Sambola et al. 2007) and deterministic (Albareda-Sambola et al. 2005) optimisation models are reported in the literature. For example, a mixed-integer programming technique is reported for minimising the sum of the fixed costs and distribution costs (Diabat and Simchi-Levi 2009) in LRP. Belenguer et al. (2011) 
propose an exact approach using a 0-1 linear model based on a branch-and-cut algorithm for solving the LRP with capacity constraints on DCs and vehicles. Rath and Gutjahr (2014) report a three-objective warehouse location-routing problem for disaster relief. Karaoglan et al. (2011) propose an exact algorithm based on a branch-and-cut technique. Berger et al. (2007) propose a branch and price algorithm. Integer-linear programming is very common in solving LRP. Applications of integer-linear programming are found in multi-level locationrouting-inventory (Ambrosino and Scutellà 2005), "road-train" routing (Semet 1995) and Eulerian location (Ghiani and Laporte 1999) etc. LRP has been viewed also as a Lagrangian relaxation model (Cappanera et al. 2004) and mixed-integer programming (Alumur and Kara 2007).

The optimisation formulations of efficient LRPs are NP-hard by nature (Nagy and Salhi 2007; Marinakis and Marinaki 2008; Yu et al. 2010). One of the characteristics of these NPhard problems is that the solution grows exponentially with increasing problem size (Erdoğan and Miller-Hooks 2012). Therefore, in order to tackle this situation, the application of metaheuristics in LRP is necessary (Golden and Skiscim 1986; Tuzun and Burke 1999; Prins et al. 2007; Bräysy et al. 2009; Prins et al. 2009). Examples on the use of meta-heuristics in LRP are abundant. This includes the use of particle swarm optimisation (Liu et al. 2012), tabu search (Russell et al. 2008), simulated annealing (Stenger et al. 2012), greedy randomised adaptive search procedure (Nguyen et al. 2012), variable neighbourhood search algorithms (Derbel et al. 2011), ant colony optimisation (Ting and Chen 2013) and honey bees mating optimisation (Marinakis et al. 2008). The use of genetic algorithms in LRPs are reported in Zhou and Liu (2007), Marinakis and Marinaki (2008), Jin et al. (2010), Karaoglan et al. (2012). Some variants of genetic algorithms are also reported in LRP literature (Hwang 2002; Zhou and Liu 2007; Marinakis et al. 2008; Jin et al. 2010). Table 2 lists some of the prominent literature on the use of meta-heuristics in LRPs.

It is reported that outbound logistics is more complicated than inbound logistics in a logistics network due to the product values, customer delivery requirements and stringent regulations (Wu and Dunn 1995). The environmental impact of product transportation to DCs and retailers can be reduced substantially with effective logistics management (Wu and Dunn 1995). Conventional logistics system does not serve this purpose effectively as it does not consider the environmental impact of the outbound logistics mechanism. Consideration of the environmental aspect of LRP in outbound logistics requires substantial changes in LRP formulation procedures.

Although literature on general sustainable operations is growing, literature specifically on sustainable location-routing is scant. Reverse logistics and green-vehicle routing methodologies are found in (Zhu et al. 2008; Erdoğan and Miller-Hooks 2012). Wang et al. (2005) reports a trade-offs model between the cost factors and the environmental impact of a supply chain. A two-layer multi-objective sustainable location-routing model with its solution approach is reported in Validi et al. (2014a, b, 2015). Literature on conventional LRPs is rich in terms of both methodologies and applications (Laporte et al. 1988; Demir et al. 2014; Prodhon and Prins 2014; Drexl and Schneider 2015). The purpose of LRP methodologies is the simultaneous determination of the location of facilities and the routes of vehicles for product transportation (Laporte et al. 1988; Yu et al. 2010). A broad range of LRP applications is found in the literature (Perl and Daskin 1985; Alumur and Kara 2007; Govindan et al. 2014). A wide range of optimisation techniques, including applications of integer-linear programming are found in literature (Semet 1995; Ambrosino and Scutellà 2005). 
Table 2 Examples of reported optimisation techniques used in location-routing problems

\begin{tabular}{|c|c|}
\hline Optimisation techniques & Publications \\
\hline Honey bees mating optimisation & Marinakis et al. (2008) \\
\hline Ant colony optimisation & $\begin{array}{l}\text { Bell and McMullen (2004), Bin et al. (2009), Ting } \\
\text { and Chen (2013), Yu and Yang (2011), Yang and } \\
\text { Zhuang (2010), Zhang et al. (2017) }\end{array}$ \\
\hline Particle swarm optimisation & $\begin{array}{l}\text { Marinakis et al. (2008), Yang and Zi-Xia (2009), } \\
\text { Liu et al. (2012), Yao et al. (2016) }\end{array}$ \\
\hline Tabu search & $\begin{array}{l}\text { Gendreau et al. (1994), Tuzun and Burke (1999), } \\
\text { Chiang and Russell (2004), Melechovský et al. } \\
\text { (2005), Albareda-Sambola et al. (2005), Lin and } \\
\text { Kwok (2006), Caballero et al. (2007), Russell } \\
\text { et al. (2008) }\end{array}$ \\
\hline Simulated annealing & $\begin{array}{l}\text { Lin et al. (2002), Wu et al. (2002), Lin and Kwok } \\
\text { (2006), Yu et al. (2010), Stenger et al. (2012) }\end{array}$ \\
\hline Greedy randomised adaptive search optimisation & $\begin{array}{l}\text { Prins et al. (2006a), Duhamel et al. (2010), Nguyen } \\
\text { et al. (2012) }\end{array}$ \\
\hline Memetic algorithm & Prins et al. (2006b), Asgari et al. (2017) \\
\hline Variable neighborhood search optimisation & $\begin{array}{l}\text { Melechovský et al. (2005), Ghodsi and Amiri } \\
\text { (2010), Derbel et al. (2011) }\end{array}$ \\
\hline Genetic algorithms & $\begin{array}{l}\text { Zhou and Liu (2007), Marinakis and Marinaki } \\
\text { (2008), Jin et al. (2010), Karaoglan et al. (2012) }\end{array}$ \\
\hline Variants of genetic algorithms & $\begin{array}{l}\text { Hwang (2002), Prins et al. (2006b), Zhou and Liu } \\
\text { (2007), Marinakis and Marinaki (2008), } \\
\text { Marinakis et al. (2008), Jin et al. (2010), } \\
\text { Karaoglan and Altiparmak (2010) }\end{array}$ \\
\hline $\begin{array}{l}\text { Imperialist competitive algorithm and variable } \\
\text { neighborhood search }\end{array}$ & Devika et al. (2014) \\
\hline Hybrid cross entropy algorithm & Wu et al. (2017) \\
\hline $\begin{array}{l}\text { Mixed integer linear programming with the classical } \\
\text { epsilon constraint technique }\end{array}$ & Toro et al. (2017) \\
\hline $\begin{array}{l}\text { Bi-objective mixed-integer non-linear programming } \\
\text { model with a modified archived multi-objective } \\
\text { simulated annealing meta-heuristic algorithm }\end{array}$ & Rayat et al. (2017) \\
\hline Two-stage stochastic programming model & Rezaee et al. (2017) \\
\hline
\end{tabular}

\subsection{Contribution and objectives}

Driven by growing social awareness, current laws and regulations and competitive business opportunities, this article contributes to the current body of knowledge by addressing a number of inter-linked decisions in logistics network design, location decisions, routing decisions and sustainability. This article contributes to the state-of-the-art of location-routing literature in the following aspects evolved from the literature review:

(a) How a bi-objective optimisation model for three-echelon distribution networks with sustainable low-cost outcome can be developed that captures several real-world factors difficult to reconcile by organisations? 
(b) How are decision makers' preferences accommodated with regard to costs and $\mathrm{CO}_{2}$ emission in optimising the logistics network design based on varying organisational strategies?

(c) What is the effective approach to solve the proposed bi-objective three-echelon locationrouting optimisation model?

To address these research aspects a sustainable three-echelon bi-objective integrated location-routing optimisation model is proposed that addresses the demand side of three echelon SCs. The weighting procedures of Analytic Hierarchy Process (AHP) (Saaty 1994) is infused into the bi-objective $0-1$ integer programming optimisation model in order to reflect the DMs' priorities in the vehicle selection decision-making process. The computational complexity of the NP-hard model necessitates the solution method to divide it into two inter-connected phases. Phase-I deals with the transportation mechanism from the processing plants to the multiple Distribution Centres (DCs) and from DCs to multiple retailers. PhaseII uses the outcome of Phase-I to locate the non-dominated Pareto realistic optimal routes among retailers. A Design of Experiment (DoE)-guided meta-heuristic-based robust solution approach, integrated with the Multi-Objective Genetic Algorithm of kind II (MOGA-II), is adopted to solve the computationally NP-hard integrated model. The final set of optimal and realistic solutions is obtained from the combination of both phases. The realistic solutions are prioritised through Technique for Order of Preference by Similarity to Ideal Solution (TOPSIS) (Hwang and Yoon 1981) by reflecting DMs' priorities. To the authors' knowledge, literature is scant in combining three inter-linked aspects of sustainable location-routing.

\section{The proposed sustainable integrated model}

The purpose of this three-echelon bi-objective sustainable model is to minimise the level of $\mathrm{CO}_{2}$ emission caused from transportation and minimise a combination of costs on the demand side of distribution networks. The proposed model is formulated based on a set of realistic assumptions. The model considers three key players on the distribution side of a SC, viz., plants, DCs and retailers. Two fleets of vehicles/trucks are considered for transporting the products throughout the SC network. A fleet of trucks transport products from plants to DCs, and another fleet of trucks transport products from DCs to retailers and then from retailers to other retailers. Each route may be a combination of different types of roads. In every country different speed limits apply to different types of roads. Speeds in different types of routes are captured in the model by the use of an appropriate variable.

The proposed model allocates DCs to the plants and retailers to DCs, and routes the vehicles from plants to DCs, DCs to retailers and retailers to retailers thereby serving the demand-side of the SC. The problem is to identify open and closed facilities and the optimised routing pattern throughout the network while minimising: (a) the $\mathrm{CO}_{2}$ emissions from transportation, and (b) the total costs of operating facilities, satisfying demand at each facility and total transportation costs. The DMs' subjective opinions are considered to identify the optimal location-routing pattern. The model is generic as it is applicable to any three-echelon logistics network.

The routes on the demand side of the SC start from plants to DCs, DCs to retailers and then from retailer to retailer. The sustainable element of the location-routing design is addressed in the model by introducing two sustainable components, viz. (i) a sustainable objective function, and (ii) an AHP-integrated sustainable constraint. 
The three-echelon bi-objective AHP-integrated 0-1 mixed integer location-routing model is associated with 10 operational constraints. A set of $0-1$ integer decision variables defines open/close plants and DCs $\left(F_{s}\right.$ and $\left.E_{j}\right)$ and all real feasible routes from plants to DCs, DCs to retailers and routes connecting retailers to retailers $\left(V_{s j t_{n} k}, L_{j i t_{n} k}\right.$ and $\left.O_{i i^{\prime} t_{n} k}\right)$. A set of parameters $\left(p_{t_{n} k_{s j}}, p_{t_{n} k_{j i}}\right.$ and $\left.p_{t_{n} k_{i i^{\prime}}}\right)$ represents the amount of $\mathrm{CO}_{2}$ emission in each real feasible route from plants to DCs, DCs to retailers, and among retailers. Two sets of variables represent the sum of fixed costs $\left(f_{s}\right.$ and $\left.f_{j}\right)$ and sum of the variable costs $\left(v_{s}\right.$ and $\left.v_{j}\right)$. Another set of parameters represents the cost of serving DCs from plants, retailers from DCs and retailers from other retailers $\left(c_{t_{n}} k_{s j}, c_{t_{n} k_{j i}}\right.$ and $\left.c_{t_{n}} k_{i i^{\prime}}\right)$ (Table 3).

\subsection{Objective functions}

The objective function (1) of the model minimises total $\mathrm{CO}_{2}$ emission from transportation between facilities i.e. plants to DCs, DCs to retailers and retailers to retailers:

$$
\text { minimise } \sum_{s \in S} \sum_{j \in J} \sum_{t_{n} \in T} \sum_{k \in K} p_{t_{n} k_{s j}} V_{s j t_{n} k}+\sum_{j \in J} \sum_{i \in I} \sum_{t_{n} \in T} \sum_{k \in K} p_{t_{n} k_{j i}} L_{j i t_{n} k}+\sum_{i \in I} \sum_{i^{\prime} \in I} \sum_{t_{n} \in T} \sum_{k \in K} p_{t_{n} k_{i i^{\prime}}} O_{i i^{\prime} t_{n} k}
$$

The objective function (2) minimises costs of operating a facility, cost of serving DCs and retailers and vehicle-routing costs:

$$
\begin{aligned}
& \operatorname{minimise}\left[\sum_{s \in S} f_{S} F_{S}+\sum_{j \in J} f_{j} E_{j}\right]+\left[\sum_{s \in S} v_{S} F_{S}+\sum_{j \in J} v_{j} E_{j}\right] \\
& +\left[\sum_{s \in S} \sum_{j \in J} \sum_{t_{n} \in T} \sum_{k \in K} c_{t_{n}} k_{s j} V_{s j t_{n} k}+\sum_{j \in J} \sum_{i \in I} \sum_{t_{n} \in T} \sum_{k \in K} c_{t_{n} k_{j i}} L_{j i t_{n} k}+\sum_{i \in I} \sum_{i^{\prime} \in I} \sum_{t_{n} \in T} \sum_{k \in K} c_{t_{n}} k_{i i^{\prime}} O_{i i^{\prime} t_{n} k}\right]
\end{aligned}
$$

\subsection{Constraints and decision variables}

Each DC is connected to only one plant, each retailer is connected to only one DC and each retailer is connected to only one other retailer (if on a multi-route):

$$
\sum_{j \in J} \sum_{t_{n} \in T} \sum_{k \in K} V_{s j t_{n} k}=1 \forall s \in S, \sum_{i \in I} \sum_{t_{n} \in T} \sum_{k \in K} L_{j i t_{n} k}=1 \forall j \in J \text { and } \sum_{i^{\prime} \in I} \sum_{t_{n} \in T} \sum_{k \in K} O_{i i^{\prime} t_{n} k}=1, \quad \forall i \in I
$$

Constraint (4) limits the length of each multi-stop route. One route comprises a start point from a DC to a retailer and then serving another retailer. Multi-stops are considered from the DCs to the retailers and from one retailer to another retailer:

$$
\sum_{j \in J} \sum_{i \in I} d_{j i} L_{j i t_{n} k}+\sum_{i \in I} \sum_{i^{\prime} \in I} d_{i i^{\prime}} O_{i i^{\prime} t_{n} k} \leq \tau_{k}, \forall k \in K, \forall t_{n} \in T
$$


Table 3 Variable and parameter definitions

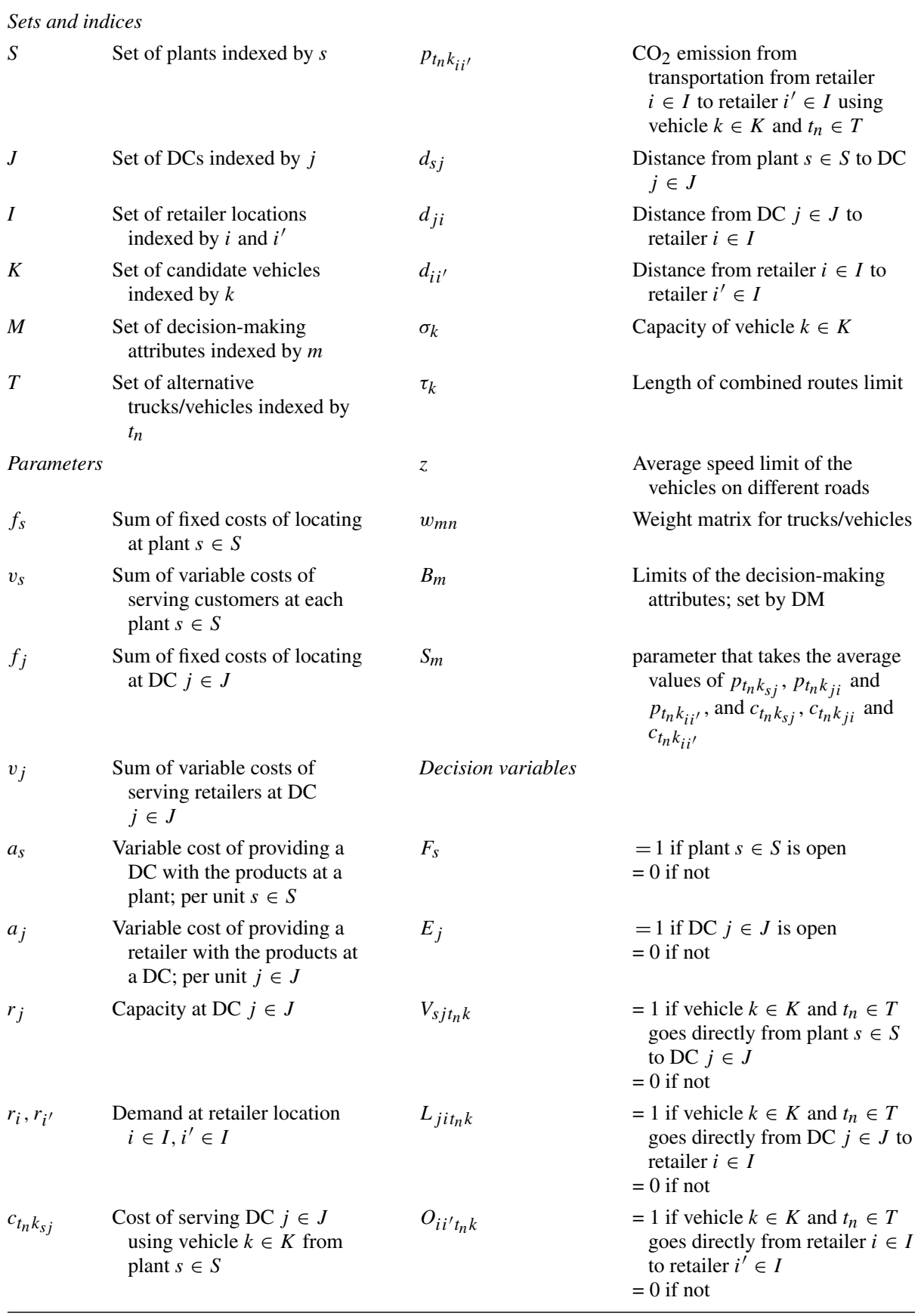


Table 3 continued

\begin{tabular}{|c|c|c|c|}
\hline$c_{t_{n} k_{j i}}$ & $\begin{array}{l}\text { Cost of serving retailer } i \in I \\
\text { using vehicle } k \in K \text { from } \\
\text { DC } j \in J\end{array}$ & $Q_{s j}$ & $\begin{array}{l}\text { Fraction of demand at plant } s \in S \\
\text { that is served by DC } j \in J\end{array}$ \\
\hline$c_{t_{n} k_{i i^{\prime}}}$ & $\begin{array}{c}\text { Cost of serving retailer } i^{\prime} \in I \\
\text { using vehicle } k \in K \text { and } \\
t_{n} \in T \text { from retailer } i \in I\end{array}$ & $Q_{j i}$ & $\begin{array}{l}\text { Fraction of demand at DC } j \in J \\
\text { that is served at retailer } i \in I\end{array}$ \\
\hline$p_{t_{n} k_{s j}}$ & $\begin{array}{l}\mathrm{CO}_{2} \text { emission from } \\
\text { transportation } t_{n} \in T_{n}, \\
\text { from plant } s \in S \text { to DC } \\
j \in J \text { using vehicle } k \in K \\
\text { and } t_{n} \in T\end{array}$ & $Q_{i i^{\prime}}$ & $\begin{array}{l}\text { Fraction of demand at retailer } \\
i \in I \text { that is served by retailer } \\
\quad i^{\prime} \in I\end{array}$ \\
\hline$p_{t_{n} k_{j i}}$ & $\begin{array}{l}\mathrm{CO}_{2} \text { emission from } \\
\text { transportation from DC } \\
j \in J \text { to retailer } i \in I \text { using } \\
\text { vehicle } k \in K \text { and } t_{n} \in T\end{array}$ & & \\
\hline
\end{tabular}

Each route on the demand side of the logistics network is connected to a facility:

$$
\begin{aligned}
& \sum_{s \in S} \sum_{j \in J} V_{s j t_{n} k} \geq 1 \quad \forall k \in K, \quad \forall t_{n} \in T \text { (routes from plant to DCs), } \\
& \sum_{j \in J} \sum_{i \in I} L_{j i t_{n} k} \geq 1 \quad \forall k \in K, \quad \forall t_{n} \in T \text { (routes from DCs to retailers), and } \\
& \sum_{i \in I} \sum_{i^{\prime} \in I} O_{i i^{\prime} t_{n} k} \geq 1, \quad \forall k \in K, \quad \forall t_{n} \in T \text { (routes from retailers to retailers). }
\end{aligned}
$$

A route entering a node (i.e., DC and retailer) must exit the same node:

$$
\begin{aligned}
& \sum_{j \in J} \sum_{i \in I} L_{j i t_{n} k}-\sum_{i \in I} \sum_{j \in J} L_{i j t_{n} k}=0, \forall k \in K, \forall t_{n} \in T \text { (from DCs to retailers) and } \\
& \sum_{i \in I} \sum_{i^{\prime} \in I} O_{i i^{\prime} t_{n} k}-\sum_{i^{\prime} \in I} \sum_{i \in I} O_{i^{\prime} i t_{n} k}=0, \forall k \in K, \forall t_{n} \in T \text { (from retailers to retailers). }
\end{aligned}
$$

The sustainable three-echelon model considers that a route can operate out of only one facility:

$$
\begin{aligned}
& \sum_{s \in S} \sum_{j \in J} V_{s j t_{n} k} \leq 1, \forall k \in K, \forall t_{n} \in T \text { (routes from plants to DCs), } \\
& \sum_{j \in J} \sum_{i \in I} L_{j i t_{n} k} \leq 1, \forall k \in K \text { (routes from DCs to retailers) } \\
& \sum_{i \in I} \sum_{i^{\prime} \in I} O_{i i^{\prime} t_{n} k} \leq 1, \forall k \in K, \forall t_{n} \in T \text { (routes connecting retailers). }
\end{aligned}
$$

The flow of the products from the supply nodes (plants and DCs) into the facilities is ensured:

$$
\begin{aligned}
& \sum_{s \in S} Q_{s j}-\sum_{j \in J} r_{j} E_{j}=0, \forall j \in J \text { (from plants to DCs), and } \\
& \sum_{j \in J} Q_{j i}-\sum_{i \in I} r_{i} E_{j}=0, \forall i \in I \text { (from DCs to retailers). }
\end{aligned}
$$


There is a restriction of throughput at each facility up to the allowable maximum limit at each node that links the flow variables to the facility location variables:

$$
\begin{aligned}
& \sum_{s \in S} Q_{s j}-r_{j} F_{s} \leq 0, \forall j \in J \text { (from plants to DCs) and } \\
& \sum_{j \in J} Q_{j i}-r_{i} E_{j} \leq 0, \forall i \in I \text { (from DCs to retailers) } .
\end{aligned}
$$

A retailer must be assigned to a facility if the route leaves the facility:

$$
\sum_{j \in J} L_{j i t_{n} k}+\sum_{i \in I} O_{i i^{\prime} t_{n} k}-Y_{j} \leq 0, \quad \forall i^{\prime} \in I, \forall j \in J, \forall k \in K, \forall t_{n} \in T
$$

Constraint (10) is applied to multi-stop routes connecting an open DC to a retailer and then through the first retailer serving other retailer(s). Assuming that the retailers have no supply of products, open DCs and routes connecting DCs to served retailers are included in this constraint.

Capacity for each vehicle is restricted:

$$
\begin{aligned}
& \sum_{j \in J} r_{j} \sum_{s \in S} V_{s j t_{n} k} \leq \sigma_{k}, \forall k \in K, \forall t_{n} \in T \text { (routes from plants to DCs), } \\
& \sum_{i \in I} r_{i} \sum_{j \in J} L_{j i t_{n} k} \leq \sigma_{k}, \forall k \in K, \forall t_{n} \in T \text { (routes from DCs to retailers), and } \\
& \sum_{i^{\prime} \in I} r_{i^{\prime}} \sum_{i \in I} O_{i i^{\prime} t_{n} k} \leq \sigma_{k}, \forall k \in K, \forall t_{n} \in T \text { (routes from DCs to retailers). }
\end{aligned}
$$

The sustainable constraint is formulated by infusing the pair-wise comparison matrices of the AHP technique into the mixed-integer programming model to introduce flexibility in the form of prioritising the vehicles to be used for the transportation:

$$
S_{m}\left(\sum_{m \in M} \sum_{n \in N} w_{m n} T_{n}\right) \leq B_{m}
$$

where $w_{m n}$ is associated with the priorities of the DMs regarding the type of vehicles $\left(T_{n}\right)$ and $B_{m}$ contributes to the parameters of the objective functions.

The decision variables are:

$$
V_{s j t_{n} k}= \begin{cases}1, & \text { if vehicle } k \in K \& t_{n} \in T \text { goes directly from plant } s \in S \text { to DC } j \in J \\ 0, & \text { if not }\end{cases}
$$$$
L_{j i t_{n} k}= \begin{cases}1, & \text { if vehicle } k \in K \& t_{n} \in T \text { goes directly from DC } j \in J \text { to retailer } i \in I \\ 0, & \text { if not }\end{cases}
$$

$O_{i i^{\prime} t_{n} k}= \begin{cases}1, & \text { if vehicle } k \in K \& t_{n} \in T \text { goes directly from retailer } i \in I \text { to retailer } i^{\prime} \in I \\ 0, & \text { if not }\end{cases}$

$$
\begin{gathered}
E_{j}= \begin{cases}1, & \text { if DC } j \in J \text { is open } \\
0, & \text { if not }\end{cases} \\
F_{s}= \begin{cases}1, & \text { if plant } \mathrm{s} \in S \text { is open } \\
0, & \text { if not }\end{cases}
\end{gathered}
$$




$$
T_{n}= \begin{cases}1, & \text { if vehicle/truck } t_{n} \in T_{n} \text { is selected to transport the products } \\ 0, & \text { if not }\end{cases}
$$

\section{Case of a dairy processing firm}

A case of a dairy processing industry's three-echelon SC, operating in the east of Ireland, is considered for implementing the model and its solution approach. The SC has 2 processing plants, 6 DCs and supplies 22 retailers. The model considers variable costs as the total costs of serving each DC at each plant and each retailer at each DC. The variable costs of the processing plants $\left(v_{s}\right)$ is defined as:

$$
v_{s}=\left(a_{s} . r_{j}\right) . V_{s j t_{n} k}
$$

where $a_{s}=$ variable cost $(€) /$ unit of product shipped from a plant to a DC; $r_{j}=$ demand (units of product) at each DC. One 'unit' refers to a two-litre carton of milk.

Variable costs at the DCs $\left(v_{j}\right)$ is defined as:

$$
v_{j}=\left(a_{j} \cdot r_{i}\right) \cdot \mathrm{L}_{j i t_{n} k},
$$

where $a_{j}=$ variable cost ( $€$ )/unit of product shipped from a supply point (here DC) to a consumption point (i.e., retailer); $r_{i}=$ demand at each retailer.

Average demand at each retailer is assumed as $2 / 3$ of the total population at the location of the retailers. Heavy duty Diesel fuelled fully loaded refrigerated vehicles are considered for the transportation activities. An average speed on the road is assumed.

The volume of burnt diesel is calculated using Eq. (21). The fuel efficiency is considered as 0.35 based on the report of the UK's Department of Energy and Climate Change (2010) and Nylund and Erkkilä (2005). Guidelines to DEFRA's (2008) greenhouse gas conversion factors aid in calculating the $\mathrm{CO}_{2}$ emission from the diesel vehicles [Eq. (22)]:

Litres of diesel burnt in each path $=$ Fuel efficiency $(\mathrm{L} / \mathrm{km}) \times$ Distance $(\mathrm{km})$

$\mathrm{CO}_{2}$ emission from a diesel vehicle $(\mathrm{kg})=$ Litres of diesel burnt $\times 2.64$

The cost of serving each of the routes from the plants to the DCs and from the DCs to the retailers is the sum of fuel costs and driver's wage. Equation (23) considers $€ 1.53 / 1$ and $€ 11.50 / \mathrm{h}$ as the cost of Diesel in Ireland and average wage of a heavy-duty vehicle driver:

$$
\begin{aligned}
\text { Cost of serving a route }= & €(1.53 \times \text { Litres of diesel bunt per } \mathrm{km}) \\
& +€\left(11.5 \times\left(\frac{\text { Disance }(\mathrm{km})}{z}\right) .\right.
\end{aligned}
$$

The variable ' $z$ ' represents the average speed in each path.

The $\mathrm{CO}_{2}$ emission during transportation between the DCs and retailers and among the retailers, and corresponding costs of serving each route $\left(p_{t_{n} k_{j i}}\right.$ and $\left.c_{t_{n} k_{j i}}\right)$ are computed. The costs of serving each route among retailers $\left(p_{t_{n} k_{i i^{\prime}}}\right.$ and $\left.c_{t_{n} k_{i i^{\prime}}}\right)$ are determined. For illustrative purpose three different types of vehicle with different levels of $\mathrm{CO}_{2}$ emission and costs, are considered for transportation.

The weight matrix $\left(w_{m n}\right)$ is determined using the pair-wise comparison matrix of AHP. The right hand side matrix of constraint (12), i.e., $B_{m}$, is found considering the average round off values of the $\mathrm{CO}_{2}$ emission. The boundary values of $\mathrm{CO}_{2}$ emission and costs of serving the routes are found. Tables 16, 17, 18, 19, 20, 21, 22, 23 and 24 of appendix provide the collated data utilised for the dairy processing industry's three-echelon SC. 


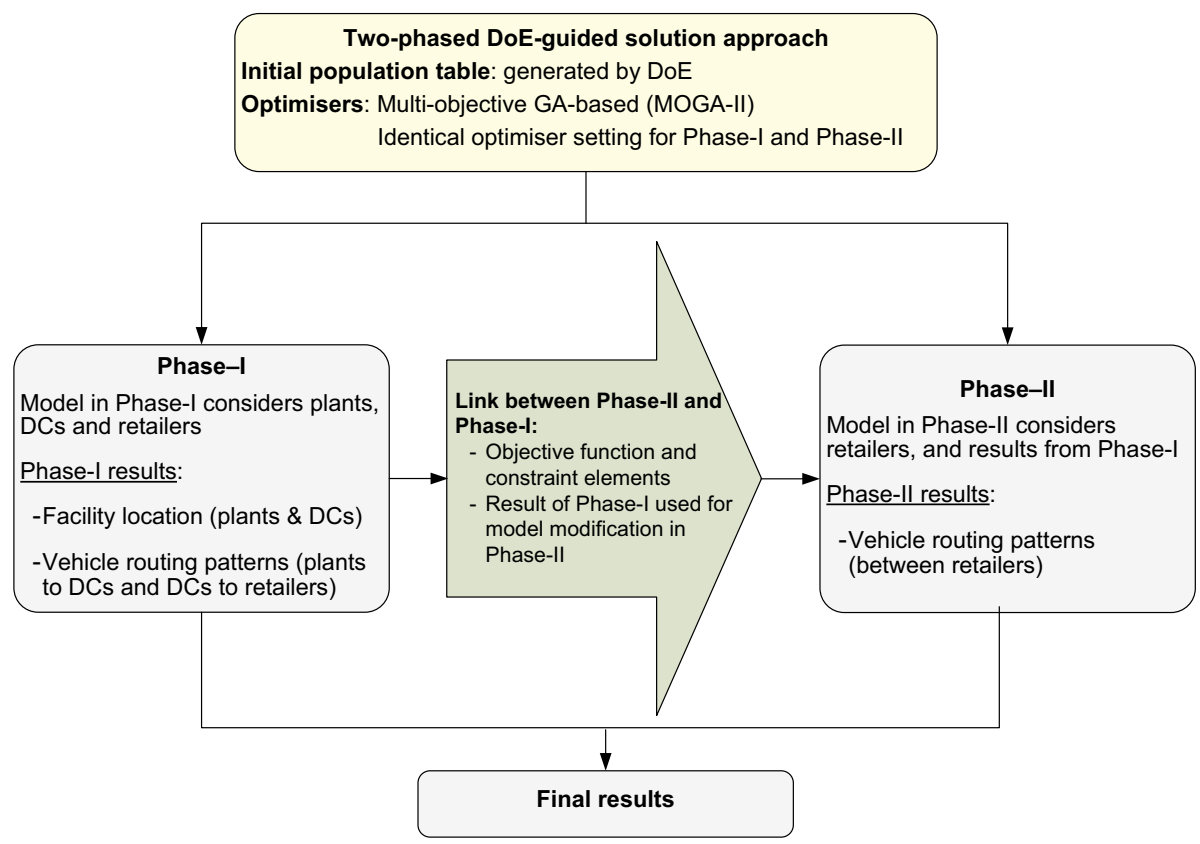

Fig. 1 Two-phased DoE-guided solution approach

\section{Two-phase solution approach}

The proposed sustainable model is NP-complete. A two-phase approach (like Przybylski et al. 2008 ) is found to be the most efficient way to solve the model. A two-phase DoE-guided solution approach (Fig. 1) has been developed to solve the proposed sustainable three-echelon model.

The model solved in Phase-I finds the optimised set of open/close plants and DCs, and the optimised routing pattern connecting open plants to open DCs and open DCs to retailers. The model solved in Phase-II uses the results from Phase-I as inputs and finds the optimised routing pattern in between the retailers. DoE is invoked during the start point of the implementation process to ensure that the MOGA-II optimiser provides the best stable solution space. Table 4 illustrates a snapshot of the technical details for the two phases.

TOPSIS is utilised to analyse the selected feasible optimal solution sets (designs) from Phase-I and Phase-II. It prioritises the results with refined result sets facilitating identification of open routes among retailers along with the type of the vehicles for transportation and its costs and $\mathrm{CO}_{2}$ emission. Phase-I of the sustainable bi-objective three-echelon locationrouting model considers a set of realistic assumptions, as illustrated in Table 5.

Vehicle routes among retailers are not considered in Phase-I. This is because of the computational difficulty for the NP-hard nature of the model. Therefore, the demands of the unserved retailers are met through other retailers in Phase-II. In order to formulate Phase-II of the model the following set of realistic assumptions are considered (Table 6). 
Table 4 A snapshot of the technical details for the two-phase sustainable three-echelon model

\begin{tabular}{|c|c|c|}
\hline \multirow[t]{5}{*}{ Phase-I } & Model scope & $\begin{array}{l}\text { 'Facility location' and 'vehicle routing' } \\
\text { within: } \\
\text { Plants } \\
\text { DCs } \\
\text { Retailers (connection between retailers not } \\
\text { considered in this phase) }\end{array}$ \\
\hline & Goals & $\begin{array}{l}\text { Facility location decision: Open/close DCs } \\
\text { (Plants are considered always open) } \\
\text { Vehicle routing decision: } \\
\text { Routes connecting plants to DCs } \\
\text { Routes connecting open DCs to retailers }\end{array}$ \\
\hline & Objective functions & $\begin{array}{l}\text { Objective function-I: Minimises } \mathrm{CO}_{2} \\
\text { emission caused form transporting } \\
\text { products between plants and DCs } \\
\text { Objective function-II: Minimises total cost } \\
\text { of operating plants and DCs and serving } \\
\text { routes }\end{array}$ \\
\hline & Constraints & $\begin{array}{l}\text { Constraint 1: Each demand node on one } \\
\text { route } \\
\text { Constraint 3: Each route to be connected to a } \\
\text { facility } \\
\text { Constraint 4: Any route entering a node must } \\
\text { exit the same node } \\
\text { Constraint 5: A route can operate out of only } \\
\text { one facility } \\
\text { Constraint 6: Defines the flow into a facility } \\
\text { from the supply points (in terms of } \\
\text { demand) } \\
\text { Constraint } 7 \text { : Restricts throughput at each } \\
\text { facility to the maximum allowed at that site } \\
\text { and links the flow variables and facility } \\
\text { location variables } \\
\text { Constraint 9: AHP-infused constraint } \\
\text { considering the stakeholders' priorities } \\
\text { Non-negativity constraints } \\
\text { Integer constraints }\end{array}$ \\
\hline & Outcomes from Phase-I & $\begin{array}{l}\text { Open/close DCs } \\
\text { Vehicle routes connecting plants to DCs } \\
\text { Vehicle routes connecting open DCs to } \\
\text { retailers }\end{array}$ \\
\hline $\begin{array}{l}\text { Link between the two } \\
\text { phases }\end{array}$ & $\begin{array}{l}\text { Results from Phase-I: Open DCs, } \\
\text { served retailers } \\
\text { Model: Constraints related to DCs } \\
\text { from Phase-I }\end{array}$ & \\
\hline \multirow[t]{2}{*}{ Phase-II } & Model scope & $\begin{array}{l}\text { 'Vehicle routing' within: } \\
\text { Open DCs and the routes connecting DCs to } \\
\text { retailers from Phase-I } \\
\text { Served retailers from Phase-I to un-served } \\
\text { retailers }\end{array}$ \\
\hline & Goal & $\begin{array}{l}\text { Vehicle routing decision: Finding routes } \\
\text { connecting served retailers to un-served } \\
\text { retailers based on the results from Phase-I }\end{array}$ \\
\hline
\end{tabular}


Table 4 continued

Objective functions

Constraints

Outcomes from Phase-II
Objective function-I: Minimises $\mathrm{CO}_{2}$ emission caused form transporting products between plants and DCs

Objective function-II: Minimises total cost of operating plants and DCs and serving routes

Constraint 1: Each demand node on one route

Constraint 2: Limits the length of each road (multi-stop vehicle routes)

Constraint 3: Each route to be connected to a facility

Constraint 4: Any route entering a node must exit the same node

Constraint 5: A route can operate out of only one facility

Constraint 6: Defines the flow into a facility from the supply points (in terms of demand)

Constraint 7: Restricts throughput at each facility to the maximum allowed at that site and links the flow variables and facility location variables

Constraint 8: If a route leaves retailer node $i \in I$ and retailer node $i^{\prime} \in I$, then retailer $i^{\prime} \in I$ must be assigned to retailer node $i \in I$ and consequently to facility (serving retailer $i \in I$ )

Constraint 9: AHP-infused constraint considering the stakeholders' priorities

Non-negativity constraints

Integer constraints

Routes connecting served retailers to un-served retailers from Phase-I

As served retailers don't supply products, the routes connecting them to open DCs from Phase-I are considered in Phase-II

\section{Results and analysis}

MOGA-II optimiser is selected to implement the sustainable bi-objective location-routing model as it has smart multi-search elitism and rapid convergence. Table 7 elucidates the optimiser parameter set up.

\subsection{Phase-I: Results and analysis}

Phase-I is implemented with an initial population of 50 different designs in the DoE table consisting of 10 DoE sequences. Phase-I is executed with 250 generations that generates 12,500 real feasible results. A statistical solution summary (Table 8) on the computed maximum and minimum levels of $\mathrm{CO}_{2}$ emission and costs based on the DoE tables is obtained. 
Table 5 Realistic assumptions considered for the design of Phase-I model

Demand side of logistics network is considered

Single product type, multiple processing plants, multiple DCs and multiple retailers based logistics channel is considered

All the processing plants remain always open

Locations of the plants, DCs and retailers are known

All routes are defined and have known start and end points

A part of the variable costs is dependent on the demand at DCs and retailers

Two fleets of vehicles are used in transportation - first fleet connects plants to DCs and the second fleet connects DCs to retailers

The number of vehicles required to transport products in each route are considered as an objective function coefficient

Each route is served by at least one vehicle

A 'node' is defined by either a DC or a retailer

Vehicles are heavy duty trucks

Refrigerated vehicles required for transportation are operated in Diesel

$\mathrm{CO}_{2}$ emission occurs during transporting products between processing plants to DCs, DCs to retailers and retailers to retailers

Fuel consumption of a vehicle is dependent on the total mass of each vehicle

Table 6 Realistic assumptions for the design of Phase-II model

Vehicle routes among retailers are only considered

Demand of each retailer is known

A vehicle can serve up to a maximum length of $400 \mathrm{~km}$

If a route opens up to cover a retailer, the demand transporting through the route is known

The number of vehicles required to transport products in each route are considered as an objective function coefficient

Table 7 MOGA-II optimiser parameter setup (Reproduced with permission from Validi 2014)

Initial population

Number of generations

Population size

Probability of directional cross-over

Probability of selection

Probability of mutation

DNA string mutation ratio

Random generator seed

Elitism

Treat constraints

Algorithm type

Initial population size
DoE guided

250

12,500

0.5

0.05

0.1

0.05

1

Enabled

Penalizing objectives

MOGA-Generational evolution 50 
Table 8 Statistical summary of different DoE tables for Phase-I

\begin{tabular}{|c|c|c|c|c|c|}
\hline \multirow{2}{*}{$\begin{array}{l}\text { Type of results in Phase-I } \\
\text { of MOGA-II optimiser }\end{array}$} & \multirow{2}{*}{$\begin{array}{l}\text { Number of real } \\
\text { feasible results }\end{array}$} & \multicolumn{2}{|c|}{$\mathrm{CO}_{2}$ emission $(\mathrm{kg})$} & \multicolumn{2}{|l|}{ Cost $(€)$} \\
\hline & & Min & $\operatorname{Max}$ & Min & Max \\
\hline Design table & 12,500 & 26,689 & 63,164 & $2,487,644$ & $2,671,661$ \\
\hline Realistic results table & 5540 & 26,689 & 45,179 & $2,487,644$ & $2,671,149$ \\
\hline $\begin{array}{l}\text { Refined realistic results } \\
\text { table }\end{array}$ & 412 & 26,689 & 45,179 & $2,487,644$ & $2,671,149$ \\
\hline Selected results table & 20 & 26,689 & 37,632 & $2,487,644$ & $2,529,290$ \\
\hline
\end{tabular}

(a)

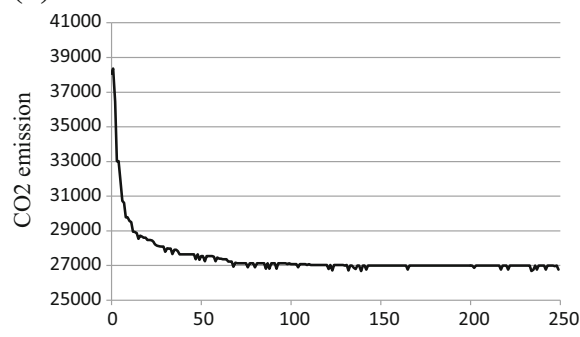

(b)

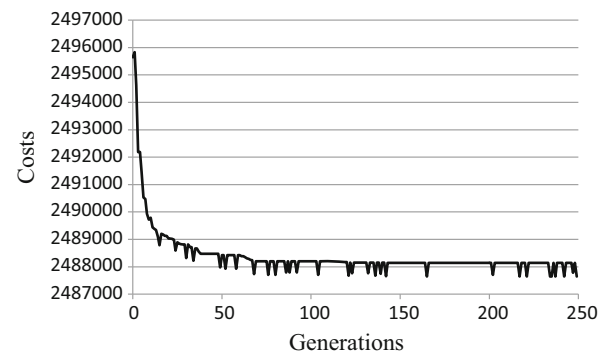

Fig. 2 Phase-I convergence for MOGA-II optimiser with reference to generations. a $\mathrm{CO}_{2}$ emission. b Costs

MOGA-II optimiser's performance is analysed using convergence plots (Fig. 2a, b). MOGA-II starts converging with mild fluctuations after 65 generations. The solution for $\mathrm{CO}_{2}$ emissions converges in a steady manner as compared with costs.

The optimiser generates a feasible space of solutions guided by the DoE tables. Figure 3a, $\mathrm{b}$ illustrates the characteristics plot of $\mathrm{CO}_{2}$ versus costs on the realistic result tables. In these plots colours and diameters of the bubbles are related to the objective functions of the model. In Fig. 3a F2 values refer to costs, whereas in Fig. 3b F1 values refer to $\mathrm{CO}_{2}$ emission. The colour schemes of the plots indicate the feasible solutions, infeasible solutions and solutions with errors. These colour schemes are illustrated in the legends of the plots. Further, the plots contain unique identity (ID) numbers in green colours. The red coloured bubbles in the plots are not realistic in nature as these solutions involve high $\mathrm{CO}_{2}$ emission and high costs. Therefore, selection of alternative solutions is confined within the blue coloured optimum realistic solutions of Fig. 3.

In order to evaluate the realistic results, 20 out of the 5540 realistic solutions are selected guided by box-whiskers. This selection refers to the results table represented by the 4-D bubble plots in Fig. 3a, b. The red coloured solutions, in the 4-D bubble plots, are not realistic in nature as those involve high $\mathrm{CO}_{2}$ emission and high costs. Therefore, selected realistic solutions are taken from the blue coloured bubbles for further evaluation using TOPSIS.

The sustainable bi-objective location-routing model for a three-echelon logistics network is a strategic decision-making procedure. In such strategic decision-making processes, it is desirable to elucidate the ranking of the set of selected feasible realistic optimal designs according to the stakeholders' preferences. Nine different weight matrices are considered to compare the selected results. It is found that extreme decision matrices are those that represent 
(a)

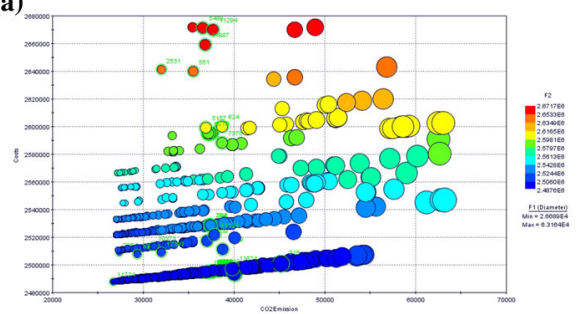

(b)

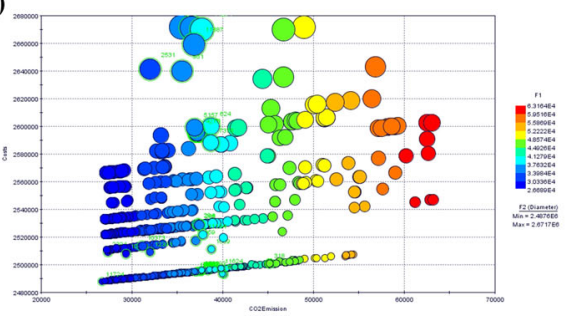

Fig. 3 Phase-I solution characteristics for $\mathrm{CO}_{2}$ emission and costs. a Costs versus $\mathrm{CO}_{2}$ emission. b Costs versus $\mathrm{CO}_{2}$ emission

Table 9 The best three results selected by TOPSIS for $W_{5}=\left(\begin{array}{ll}0.5 & 0.5\end{array}\right)$ weight matrix

\begin{tabular}{lll}
\hline Rank & $\mathrm{CO}_{2}$ emission $(\mathrm{kg})$ & Costs $(€)$ \\
\hline 1st & 26,689 & $2,487,644$ \\
2nd & 27,354 & $2,509,288$ \\
3rd & 29,354 & $2,507,950$ \\
\hline
\end{tabular}

a situation where the stakeholder believes minimising $\mathrm{CO}_{2}$ emissions is more important and minimisation of costs is less important to the stakeholder, or vice versa. Therefore, using a moderate weight matrix $W_{5}=\left(\begin{array}{ll}0.5 & 0.5\end{array}\right)$ in TOPSIS the selected results are prioritised. 20 results out of 412 realistic results generated by MOGA-II are selected using TOPSIS and the top three selected designs are shown in Table 9.

A routing scheme for the first ranked result is obtained (Table 10). Further, in order to perform a test on the robustness of the model a scenario analysis (Table 11) on the closed routes is conducted. This scenario analysis for Phase-I of the model shows the effect on the $\mathrm{CO}_{2}$ emission and total costs if the closed routes are open considering the moderate TOPSIS weight matrix, viz., $W_{5}=\left(\begin{array}{ll}0.5 & 0.5\end{array}\right)$.

Performance evaluation of MOGA-II shows that the 20 selected results lie on the Pareto frontier (Fig. 4) that follows the Pareto optimality, and it is very efficient.

\subsection{Phase-II: Results and analysis}

Phase-I of the model provides information on the open and closed DCs, routes the processing plants to the open DCs and routes the open DCs to the open retailers. The physical significance of the Phase-II of the model is to locate the open retailer routes and serve the un-served open retailers from Phase-I through other open retailers based on the constraints of the model. Therefore, the results from Phase-I are utilised in Phase-II. Although the capability of the Phase-II of the model is to provide solutions for all the selected realistic solutions, in this article the first-ranked solution of Phase-I is used as a representative case.

The selected result from Phase-I is the first ranked result. The corresponding $\mathrm{CO}_{2}$ emission and costs are 26,689 $\mathrm{kg}$ and $€ 2,487,644$ respectively. The open DCs are DC\#3 and DC\#5, and the open routes are $\mathrm{V}_{\mathrm{I} 2}, \mathrm{~V}_{\mathrm{I} 3}, \mathrm{~V}_{\mathrm{I} 4}, \mathrm{~V}_{\mathrm{II} 1}, \mathrm{~V}_{\mathrm{II} 5}, \mathrm{~V}_{\mathrm{II} 6}, \mathrm{~L}_{302}, \mathrm{~L}_{303}, \mathrm{~L}_{304}, \mathrm{~L}_{305}, \mathrm{~L}_{306}, \mathrm{~L}_{307}$, $\mathrm{L}_{311}, \mathrm{~L}_{318}, \mathrm{~L}_{321}, \mathrm{~L}_{501}, \mathrm{~L}_{509}, \mathrm{~L}_{510}, \mathrm{~L}_{512}, \mathrm{~L}_{516}, \mathrm{~L}_{517}, \mathrm{~L}_{519}, \mathrm{~L}_{520}$ and $\mathrm{L}_{522}$. In Phase-I the routes 
Table 10 Routing scheme in Phase-I for the top ranked three results

\begin{tabular}{|c|c|c|c|c|}
\hline Result (design) & Open routes & $\begin{array}{l}\text { Transportation } \\
\text { option }\end{array}$ & $\mathrm{CO}_{2}$ emission & Costs \\
\hline 1st ranked & $\begin{array}{l}\text { Plant-I to: DCs } 2,3 \\
\text { Plant-II to: DCs } 1,4,5,6 \\
\text { Open DCs: } 3,5 \\
\text { DC } 3 \text { serving retailers: } 02,03,04,05 \text {, } \\
\quad 06,07,11,13,18,21 \\
\text { DC } 5 \text { serving retailers: } 1,9,10,12, \\
\quad 16,17,19,20,22\end{array}$ & $\mathrm{~T}_{2}$ & 26,689 & $2,487,644$ \\
\hline 2nd ranked & $\begin{array}{l}\text { Plant-I to: DC } 2,3,4 \\
\text { Plant-II to: DC } 1,5,6 \\
\text { Open DCs: } 1,3,5 \\
\text { DC } 1 \text { serving retailers: } 02,08 \\
\text { DC } 3 \text { serving retailers: } 03,04,05,06 \text {, } \\
\quad 07,11,18 \\
\text { DC } 5 \text { serving retailers: } 1,9,12,16, \\
\quad 17,20\end{array}$ & $\mathrm{~T}_{3}$ & 27,354 & $2,509,288$ \\
\hline 3rd ranked & $\begin{array}{l}\text { Plant-I to: DCs } 1,2,3,4 \\
\text { Plant-II to: DCs } 5,6 \\
\text { Open DCs: } 1,3,5 \\
\text { DC } 1 \text { serving retailers: } 01,02,03,19 \\
\text { DC } 3 \text { serving retailers: } 05,07,08,09 \text {, } \\
\quad \text { 10,11, 20, } 21,22 \\
\text { DC } 5 \text { serving retailers: } 06,12\end{array}$ & $\mathrm{~T}_{3}$ & 29,354 & $2,507,950$ \\
\hline
\end{tabular}

connecting DC \#3 to the retailers 02, 03, 04, 05, 06, 07, 11, 18 and 21 and DC \#5 to the retailers $01,09,10,12,16,17,19,20$ and 22 are served. Therefore, retailers $08,13,14$ and 15 are left un-served. The MOGA-II optimiser is again executed to solve the Phase-II of the model with 250 generations and 50 different results on DoE table. A statistical summary for Phase-II is elucidated in Table 12.

A feasible space of solutions guided by the DoE tables is obtained (Fig. 5a, b) illustrating linear relationships between $\mathrm{CO}_{2}$ emission and costs. The objective functions of the model solved in Phase-II do not consider plants and DCs as they were already covered in Phase-I. Therefore, the fixed and variable costs of operating plant and DCs and the $\mathrm{CO}_{2}$ emissions from transportation (plants to DCs) are not considered in these objective functions. The feasible and optimal results are chosen from the blue coloured bubbles of Fig. 5 guided by a set of history diagrams and box-whisker plots.

A total of 20 selected results are prioritised by TOPSIS using weight matrix $W_{5}=$ ( 0.50 .5 ), and the top three are picked for further analysis. These three results cover the rest of the retailers. Phase-II of the solution approach is designed to find the optimal realistic designs for serving the following un-served retailers from Phase-I, viz. retailers \#08, 13, 14 and 15. Considering these three results, open routes among retailers are identified along with the type of the vehicles used for transportation and their corresponding costs and $\mathrm{CO}_{2}$ emission (Table 13).

\subsection{Final results}

The final result is a combination of the Phase-I and Phase-II results. Table 14 presents the sustainable location-routing plan while Table 15 shows the number of vehicles and the 
Table 11 Scenario analysis for the first ranked result from Phase-I

\begin{tabular}{|c|c|c|}
\hline All routes & $\mathrm{CO}_{2}$ emission if route opens & Costs if route opens \\
\hline \multicolumn{3}{|c|}{ Processing plants to DCs } \\
\hline \multicolumn{3}{|l|}{ Plant-I } \\
\hline DC 1 & 1836 & 1296 \\
\hline DC 2 & & - \\
\hline DC 3 & - & - \\
\hline DC 4 & 7236 & 5226 \\
\hline DC 5 & 2585 & 1927 \\
\hline DC 6 & 4422 & 3216 \\
\hline \multicolumn{3}{|l|}{ Plant-II } \\
\hline DC 1 & - & - \\
\hline DC 2 & 6834 & 5025 \\
\hline DC 3 & 13,534 & 9514 \\
\hline \multicolumn{3}{|l|}{ DC 4} \\
\hline DC 5 & - & - \\
\hline DC 6 & - & - \\
\hline \multicolumn{3}{|c|}{ DCs to retailers } \\
\hline \multicolumn{3}{|l|}{ DC 3} \\
\hline Retailer 1 & 92 & 56 \\
\hline Retailer 2 & - & - \\
\hline Retailer 3 & - & - \\
\hline Retailer 4 & - & - \\
\hline Retailer 5 & - & - \\
\hline Retailer 6 & - & - \\
\hline Retailer 7 & - & - \\
\hline Retailer 8 & 87 & 61 \\
\hline Retailer 9 & 40 & 28 \\
\hline Retailer 10 & 65 & 48 \\
\hline Retailer 11 & - & - \\
\hline Retailer 12 & 28 & 21 \\
\hline \multicolumn{3}{|l|}{ Retailer 13} \\
\hline Retailer 14 & 435 & 291 \\
\hline Retailer 15 & 163 & 105 \\
\hline Retailer 16 & 226 & 142 \\
\hline Retailer 17 & 121 & 72 \\
\hline Retailer 18 & - & - \\
\hline Retailer 19 & 48 & 48 \\
\hline Retailer 20 & 130 & 100 \\
\hline Retailer 21 & - & - \\
\hline Retailer 22 & 228 & 168 \\
\hline \multicolumn{3}{|l|}{ DC 5} \\
\hline Retailer 1 & - & - \\
\hline Retailer 2 & 216 & 152 \\
\hline
\end{tabular}


Table 11 continued

\begin{tabular}{|c|c|c|}
\hline All routes & $\mathrm{CO}_{2}$ emission if route opens & Costs if route opens \\
\hline Retailer 3 & 140 & 98 \\
\hline Retailer 4 & 108 & 79 \\
\hline Retailer 5 & 44 & 26 \\
\hline Retailer 6 & 56 & 37 \\
\hline Retailer 7 & 34 & 24 \\
\hline Retailer 8 & 96 & 68 \\
\hline Retailer 9 & - & - \\
\hline Retailer 10 & - & - \\
\hline Retailer 11 & 40 & 33 \\
\hline Retailer 12 & - & - \\
\hline Retailer 13 & 173 & 122 \\
\hline Retailer 14 & 501 & 354 \\
\hline Retailer 15 & 157 & 115 \\
\hline Retailer 16 & - & - \\
\hline Retailer 17 & - & - \\
\hline Retailer 18 & 90 & 55 \\
\hline Retailer 19 & - & - \\
\hline Retailer 20 & - & - \\
\hline Retailer 21 & 336 & 204 \\
\hline Retailer 22 & - & - \\
\hline
\end{tabular}

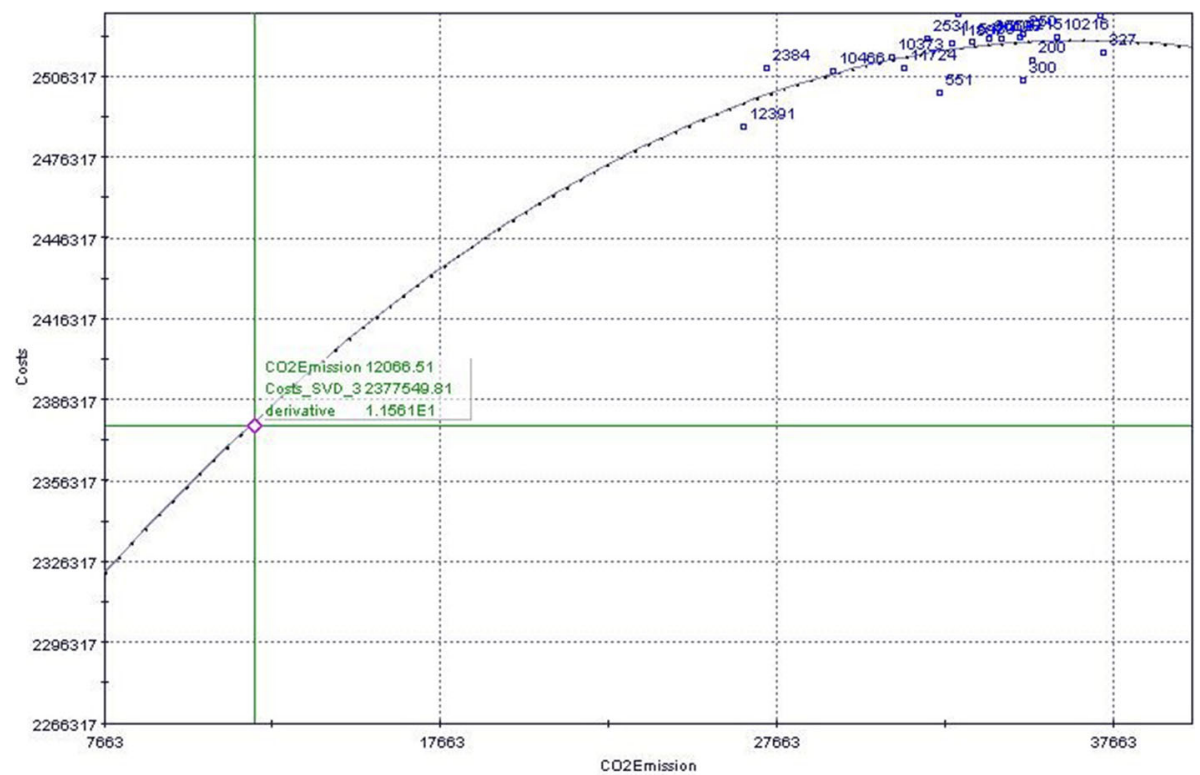

Fig. 4 Pareto optimal frontier for selected results in Phase-I 
Table 12 Statistical summary of different DoE tables for Phase-II

\begin{tabular}{|c|c|c|c|c|c|}
\hline \multirow{2}{*}{$\begin{array}{l}\text { Result types for Phase-II } \\
\text { of MOGA-II optimiser }\end{array}$} & \multirow[t]{2}{*}{ Number of results } & \multicolumn{2}{|c|}{$\mathrm{CO}_{2}$ emission $(\mathrm{kg})$} & \multicolumn{2}{|c|}{ Costs $(€)$} \\
\hline & & Min & $\operatorname{Max}$ & Min & $\operatorname{Max}$ \\
\hline Results table & 12,500 & 988 & 3622 & 701 & 2515 \\
\hline Realistic results table & 3499 & 988 & 1778 & 701 & 1245 \\
\hline $\begin{array}{l}\text { Refined realistic results } \\
\text { table }\end{array}$ & 399 & 988 & 1778 & 701 & 1245 \\
\hline Selected results table & 20 & 988 & 1514 & 701 & 1031 \\
\hline
\end{tabular}

(a)

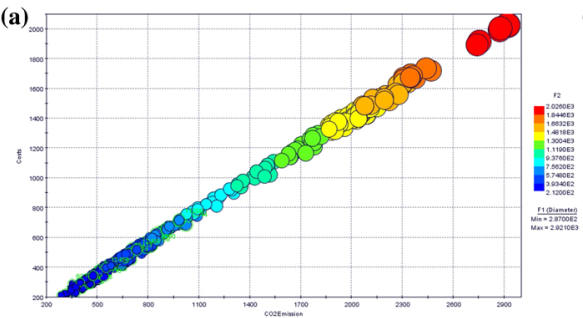

(b)

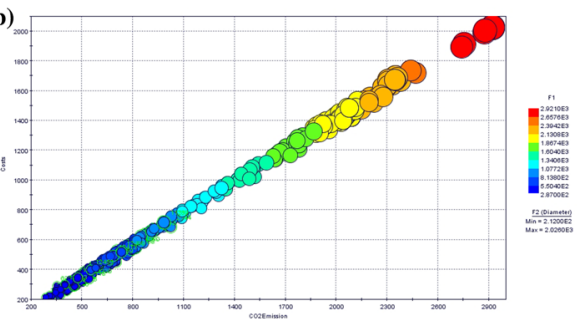

Fig. 5 Phase-II solution characteristics for $\mathrm{CO}_{2}$ emission and costs. a Costs versus $\mathrm{CO}_{2}$ emission. b Costs versus $\mathrm{CO}_{2}$ emission

Table 13 Analysis of the TOPSIS-prioritised designs in Phase-II

\begin{tabular}{|c|c|c|c|c|}
\hline Results & Open routes & Vehicle type & $\mathrm{CO}_{2}$ emission $(\mathrm{kg})$ & Costs $(€)$ \\
\hline 1st ranked & $\begin{array}{l}\text { O0608, O1613, } \\
\text { O1714, O1415 }\end{array}$ & $\mathrm{T} 2$ & 988 & 701 \\
\hline 2 ranked & $\begin{array}{l}\text { O0608, O1613, } \\
\text { O1315, O1714 }\end{array}$ & $\mathrm{T} 3$ & 1036 & 722 \\
\hline 3 ranked & $\begin{array}{r}\text { O0408, O1613, } \\
\text { O1714, O1415 }\end{array}$ & $\mathrm{T} 3$ & 1058 & 755 \\
\hline
\end{tabular}

transported quantities in each open route for the first ranked result from Phase-I which was solved in Phase-II.

It is noted that the selected 20 different optimal and feasible design IDs for Phase-II of the integrated model (as shown in Table 12) lie on the Pareto front (Fig. 6).

The selected 20 different optimal and feasible results (designs) for Phase-II of the integrated model lie on the Pareto front (Fig. 6). The realistic optimum routes from the processing plants, through DCs, to the retailers are mapped in Fig. 7. Figure 7 is an illustrative example of the final results for the proposed sustainable three-echelon bi-objective location-routing model for the demand side of the supply chain. 
Table 14 The sustainable location-routing plan

\begin{tabular}{|c|c|c|c|c|c|}
\hline \multicolumn{2}{|l|}{ Phase-I } & \multicolumn{2}{|l|}{ Phase-II } & \multirow[t]{2}{*}{$\mathrm{CO}_{2}$ emission } & \multirow[t]{2}{*}{ Costs } \\
\hline Open routes & Vehicle type & Open routes & Vehicle type & & \\
\hline $\begin{array}{l}\text { Plant-I to: DC } 2 \text { and DC } 3 \\
\text { Plant-II to: DC } 1, \text { DC } 4, \text { DC } 5 \\
\text { and DC } 6 \\
\text { Open DCs: DC } 3 \text { and DC } 5 \\
\text { DC } 3 \text { serving retailers: } 02,03 \text {, } \\
04,05,06,07,11,13,18 \\
\text { and } 21 \\
\text { DC } 5 \text { serving retailers: } 01,09 \text {, } \\
10,16,17,19,20 \text { and } 22\end{array}$ & $\mathrm{~T}_{2}$ & $\begin{array}{l}\text { Retailer } 06 \text { to } \\
\text { retailer } 08 \\
\text { Retailer } 16 \text { to } \\
\text { retailer } 13 \\
\text { Retailer } 17 \text { to } \\
\text { retailer } 14 \\
\text { Retailer } 14 \text { to } \\
\text { retailer } 15\end{array}$ & $\mathrm{~T}_{2}$ & 27,677 & $2,488,345$ \\
\hline
\end{tabular}

\section{Managerial implications}

The supply chain distribution system consists of processing plants, DCs and retailers. The considered case is representative of many other real-world logistics networks with intermediate DCs between production facilities and retailers. With the help of this three-echelon bi-objective AHP-integrated location-routing model logistics managers will be able to allocate DCs to the plants and retailers to DCs, and routes the vehicles from plants to DCs, DCs to retailers and retailers to retailers. By using the model and its solution approach logistics managers can identify open and closed facilities and the optimised routing pattern throughout the network. The optimised routing pattern provides two advantages to managers while satisfying the demand at each facility and total transportation costs, viz. minimisation of (a) $\mathrm{CO}_{2}$ emissions from transportation, and (b) total costs of operating facilities. The logistics managers can utilise the benefits from this model as it captures several real-world factors that organisations find difficult to reconcile. The proposed model bridges the gap between the existing distribution solutions and the environmental impact of distribution. The model considers capacities of the processing plants, DCs, retailers and the routes connecting them and allocates plants to DCs, DCs to retailers and retailer to retailers suitably. The routing of the vehicles serves the demand-side of the $\mathrm{SC}$ and simultaneously minimises the $\mathrm{CO}_{2}$ emissions from the vehicles during transportation. Both the fixed and variable costs have been optimised. Further, the model eliminates organisational estimation from contrasting objectives (i.e. cost versus environmental impact). The sustainable model has been designed to be robust with an ability for logistics managers to take immediate decisions by opening alternative closed feasible routes during SC disruptions.

\section{Conclusions}

From a practical viewpoint, sustainable business development has become the norm for general organisational development. Such organisational activity is generally driven by necessity rather than for altruistic reasons. Such developments are generally driven by a combination of dictate (e.g. legislative rules and polluter pay principles), competitive pressures (e.g. consumers and competitors) and for identified efficiencies (e.g. reduced cost of operations). This article contributes to this growing sustainable business development domain through the formulation of a sustainable location-routing solution approach for a three-echelon logistics network. More specifically, an innovative sustainable integrated bi-objective $0-1$ mixed- 
Table 15 Transported quantities and the number of vehicles in open routes

\begin{tabular}{|c|c|c|}
\hline Open routes & Quantity shipped & Number of vehicles \\
\hline \multicolumn{3}{|l|}{ Plants to DCs } \\
\hline \multicolumn{3}{|l|}{ Plant-I } \\
\hline DC 2 & 800,000 & 67 \\
\hline DC 3 & $1,000,000$ & 67 \\
\hline DC 4 & $1,000,000$ & 67 \\
\hline \multicolumn{3}{|l|}{ Plant-II } \\
\hline DC 1 & $1,000,000$ & 54 \\
\hline DC 5 & 700,000 & 47 \\
\hline DC 6 & $1,000,000$ & 67 \\
\hline \multicolumn{3}{|l|}{ DCs to retailers } \\
\hline \multicolumn{3}{|l|}{ DC 3} \\
\hline Retailer 02 & 25,000 & 2 \\
\hline Retailer 03 & 19,000 & 2 \\
\hline Retailer 04 & 9000 & 1 \\
\hline Retailer 05 & 14,000 & 1 \\
\hline Retailer 06 & $14,500+9000$ & 2 \\
\hline Retailer 07 & 10,000 & 1 \\
\hline Retailer 11 & 7000 & 1 \\
\hline Retailer 18 & 7000 & 1 \\
\hline Retailer 21 & 182,000 & 13 \\
\hline \multicolumn{3}{|l|}{ DC 5} \\
\hline Retailer 01 & 25,000 & 2 \\
\hline Retailer 09 & 21,000 & 2 \\
\hline Retailer 10 & 9000 & 1 \\
\hline Retailer 12 & 11,000 & 1 \\
\hline Retailer 16 & $16,000+12,000$ & 2 \\
\hline Retailer 17 & $13,000+35,000+7,000$ & 4 \\
\hline Retailer 19 & 350,000 & 24 \\
\hline Retailer 20 & 138,000 & 10 \\
\hline Retailer 21 & 177,000 & 12 \\
\hline \multirow[t]{3}{*}{ Retailers connections } & Retailer 06 to retailer 08 & \\
\hline & Retailer 16 to retailer 13 & \\
\hline & Retailer 17 to retailer 14 to retailer 15 & \\
\hline Total $\mathrm{CO}_{2}$ emission $(\mathrm{kg})$ & $26,689+988=27,677$ & \\
\hline Total Costs $(€)$ & $2,487,644+701=2,488,345$ & \\
\hline
\end{tabular}

integer programming method has been presented based for the three-echelon dairy processing logistics network. The implemented solution approach consists of a DoE guided efficient genetic algorithm based meta-heuristic with TOPSIS being used for the purpose of ranking sets of selected results. The solution approach has been developed to allow decision makers to develop routing plans based on varying organisational strategies. For example, decision makers can input into the model their own organisational preferences in terms of the influence of costs with respect to environmental performance. Organisations that face strong environ- 


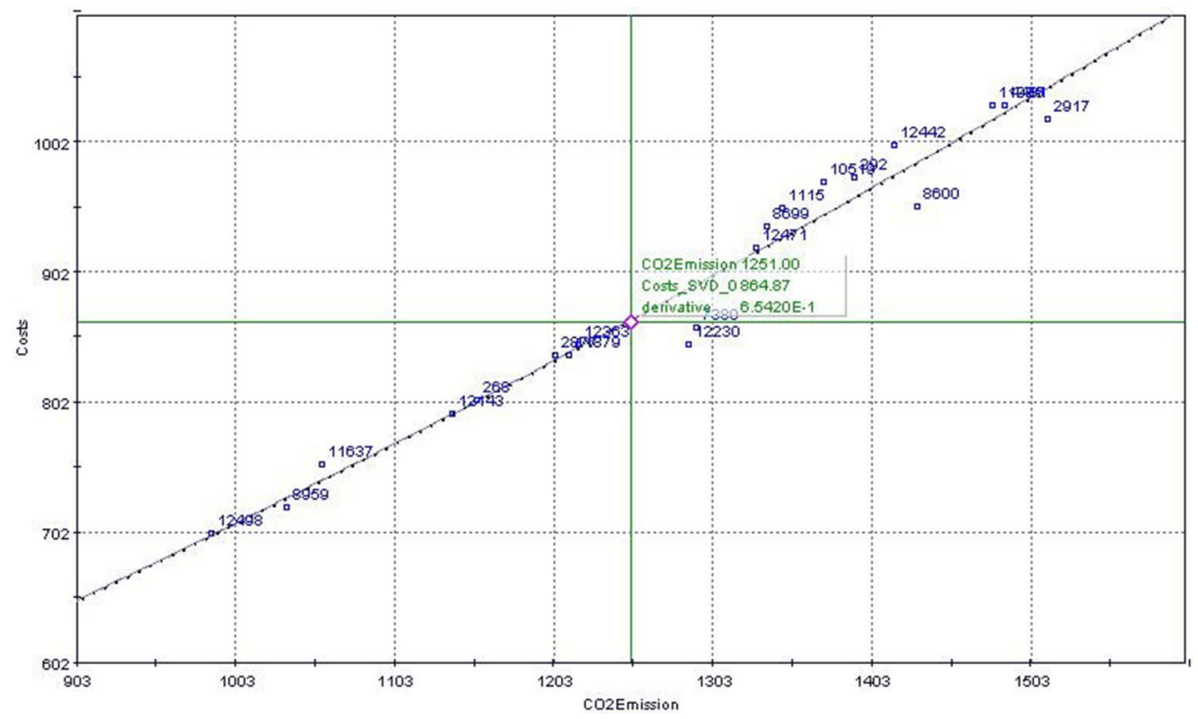

Fig. 6 Pareto optimal front for selected results in Phase-II
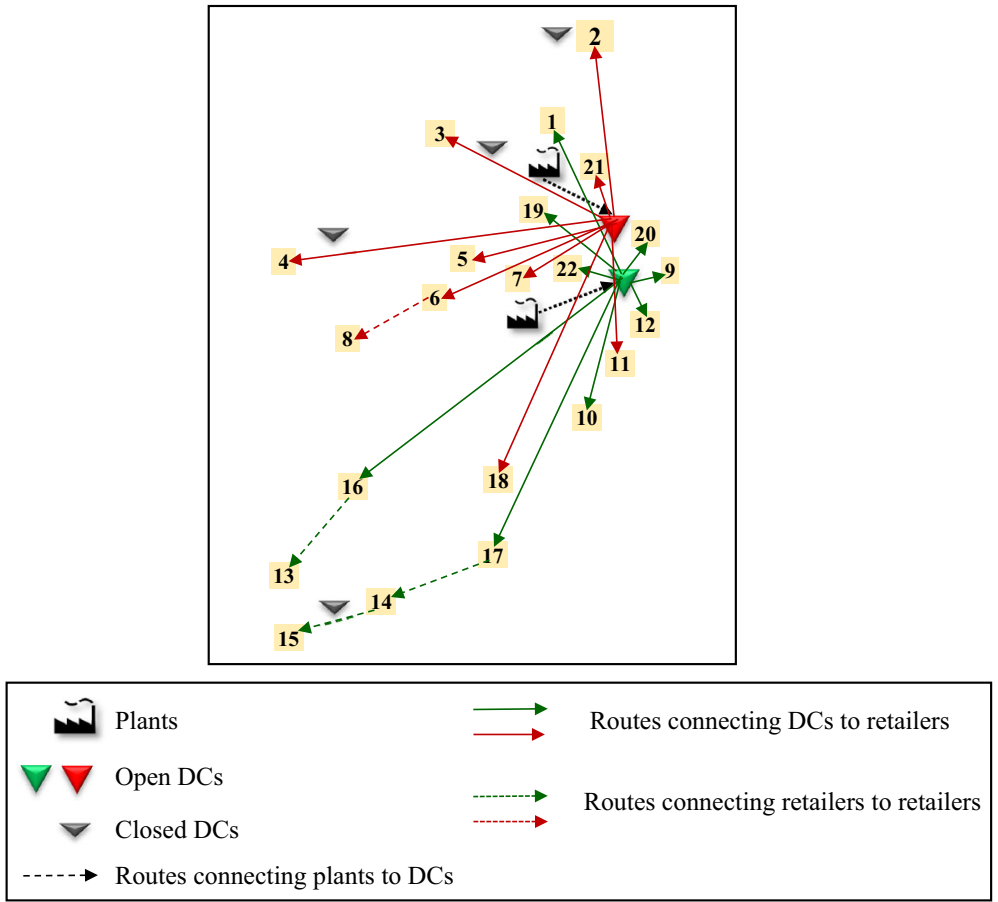

Fig. 7 Schematic representation of the sustainable location-routing pattern

mental influences (e.g. consumer pressure, legislation, etc.) can place a heavier weight on this factor through AHP in the model. Likewise, an organisation that favours cost or even a more balanced approach can influence these in similar fashions. Each setup of the model will provide a set of results that are attuned to the organisations strategic preferences. 
The model presented in this paper has been specifically tested in the case of the threeechelon dairy logistics network. Although this model has been illustrated in this way, the underlying DoE-guided unique solution approach and the analysis procedure do not have any geographical nor specific structural limitations in terms of the number of entities in each of the three echelons (e.g. processing plants, DCs, retailers). In short, the sustainable bi-objective three-echelon location-routing model, its solution approach and analysis procedure can be implemented to any three-echelon logistics network.

\subsection{Future scope of research}

The presented model clearly presents a novel procedure for evaluating the bi-objectives, viz. cost and environmental impact associated with $\mathrm{CO}_{2}$ emissions for logistics distribution system. Although the model is innovative in nature and extends the current LRP domain, there are a number of extensions which would add additional value. In the first instance a fourth echelon to the model, incorporating grocery shops/super markets would be a useful extension to the current presented model. Furthermore, an extension to the current representation of environmental impact as $\mathrm{CO}_{2}$ emissions would provide for a more comprehensive depiction. Such an extended representation could include the introduction of carbon taxes, carbon caps and trading and carbon offsets in the proposed model using appropriate objective functions. In addition, collaborative partnership among the multiple processing plants, distribution centres and retailers also provides opportunity for future research. The proposed model does not currently consider variability of demand under dynamic conditions. The variability in demand could possibly have a significant effect on the selection of the type of vehicle based on capacity. Concerns over the NP-hardness of the current model limited the inclusion of demand variability in the proposed methodology, but would be a useful area for further research. Inclusion of uncertainty issues can also be another area for future research directions. Uncertain issues like catastrophes can be used in the dynamic model to detect the vulnerability of individual nodes (i.e., open and closed routes).

Acknowledgements The authors sincerely convey thanks to the anonymous reviewers for their constructive comments. A portion of this article is adopted from the funded Ph.D. project of Dr. Sahar Validi conducted and awarded at Dublin City University Business School, Republic of Ireland.

Open Access This article is distributed under the terms of the Creative Commons Attribution 4.0 International License (http://creativecommons.org/licenses/by/4.0/), which permits unrestricted use, distribution, and reproduction in any medium, provided you give appropriate credit to the original author(s) and the source, provide a link to the Creative Commons license, and indicate if changes were made.

\section{Appendix}

See Tables 16, 17, 18, 19, 20, 21, 22, 23 and 24. 
Table 16 Locations of the plants, DCs and retailers (Validi 2014)

\begin{tabular}{ll}
\hline SC elements & Geographical locations \\
\hline Plants (2 numbers) & Drogheda, Ballitore \\
Distribution Centres (6 numbers) & Dundalk, Drogheda, Dublin City, Tullamore, Bray, Waterford \\
Customers (22 numbers) & Drogheda, Dundalk, Navan, Tullamore, Naas, Newbridge, Leixlip, \\
& Port Laoise, Bray, Arklow, Wicklow, Greystones, Clonmel, \\
& Waterford, Tramore, Kilkenny, Wexford, Ennoscorthy, Dublin \\
& City, Dun Laogharie/Rathdawn, Fingal, South Dublin \\
\hline
\end{tabular}

Table 17 Costs for operating plants (Validi 2014)

\begin{tabular}{lll}
\hline & Plants & \\
\cline { 2 - 3 } & Plant-I (Drogheda) & Plant-II (Ballitore) \\
\hline Fixed costs $(€)$ & 1500 & 2000 \\
Variable costs per unit $\left(v_{S}\right)(€)$ & 0.20 & 0.24 \\
\hline
\end{tabular}

Table 18 Costs for distribution centres (Validi 2014)

\begin{tabular}{lllllll}
\hline \multicolumn{7}{c}{ Distribution centres (DCs) } \\
\cline { 2 - 7 } & $\begin{array}{l}\text { DC a } \\
\text { Dundalk }\end{array}$ & $\begin{array}{l}\text { DC b } \\
\text { Drogheda }\end{array}$ & $\begin{array}{l}\text { DC c } \\
\text { Dublin City }\end{array}$ & $\begin{array}{l}\text { DC d } \\
\text { Tullamore }\end{array}$ & $\begin{array}{l}\text { DC e } \\
\text { Bray }\end{array}$ & DC f Waterford \\
\hline $\begin{array}{l}\text { Fixed costs }(€) \\
\begin{array}{l}\text { Variable costs per unit }(€) \\
\left(v_{j}\right)\end{array}\end{array}$ & 0.02 & 0.03 & 0.03 & 0.03 & 0.01 & 0.04 \\
\hline
\end{tabular}

Table 19 Capacity of the distribution centres (Validi 2014)

\begin{tabular}{ll}
\hline DCs & Capacity (unit)
\end{tabular}
a. Dundalk
800,000
b. Drogheda
$1,000,000$
c. Dublin City
$1,000,000$
d. Tullamore
$1,000,000$
e. Bray
700,000
f. Waterford
$1,000,000$

Table 20 Speed limits and average speeds of the vehicles (Validi et al. 2014a, b, 2015; Validi 2014)

\begin{tabular}{llr}
\hline Type of road & $\begin{array}{l}\text { Speed limits in } \mathrm{km} / \mathrm{h} \text { (as per Road } \\
\text { Traffic Act 2004) }\end{array}$ & Average speeds $(\mathrm{km} / \mathrm{h})$ \\
\hline Motorway & 120 & 100 \\
$\begin{array}{l}\text { National primary and secondary routes } \\
\quad \text { (dual carriageways included) }\end{array}$ & 100 & 80 \\
Regional and local roads & 80 & 50 \\
Built up areas (town and city) & 50 & 30 \\
\hline
\end{tabular}




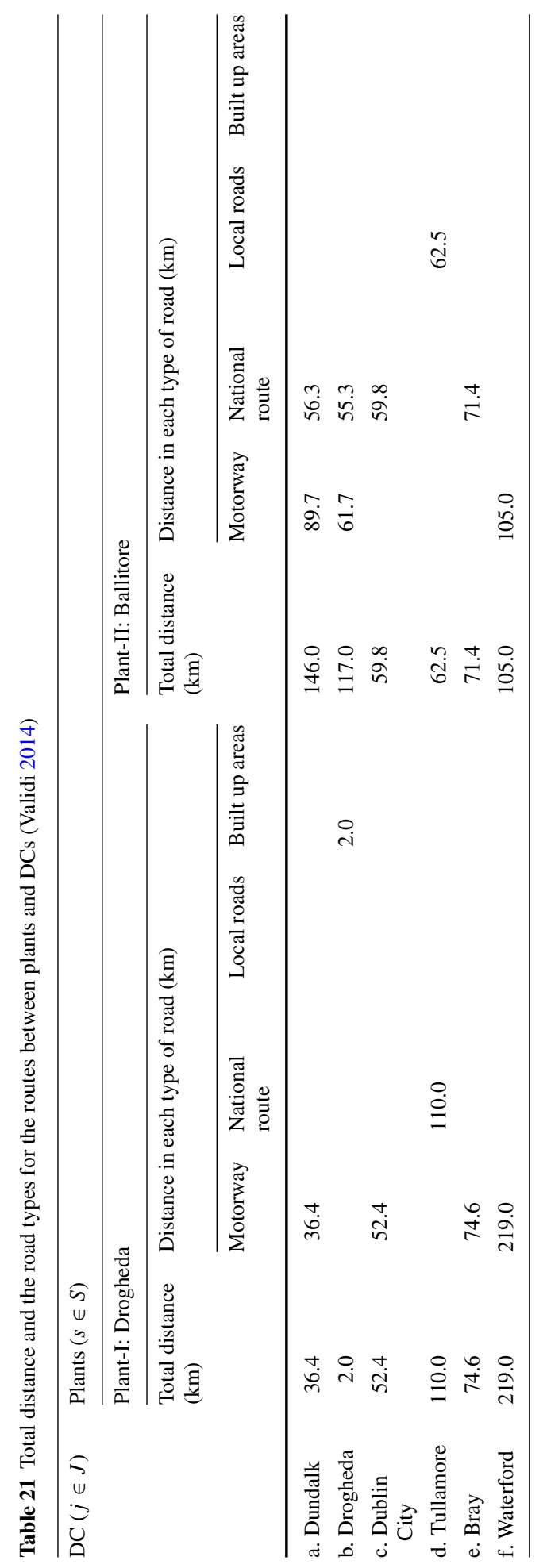


Table 22 Vehicle types (Validi et al. 2014a, b, 2015; Validi 2014)

\begin{tabular}{lll}
\hline Vehicle type & $\mathrm{CO}_{2}$ emission & Costs \\
\hline Vehicle-1 $\left(\mathrm{T}_{1}\right)$ & Medium & Medium \\
Vehicle-2 $\left(\mathrm{T}_{2}\right)$ & Low & High \\
Vehicle-3 $\left(\mathrm{T}_{3}\right)$ & High & Low \\
\hline
\end{tabular}

\begin{tabular}{lllll}
\hline Attributes & \multicolumn{4}{l}{ Candidate-alternatives } \\
\cline { 2 - 5 } & $\mathrm{T} 1$ & $\mathrm{~T} 2$ & $\mathrm{~T} 3$ & Sum \\
\hline $\begin{array}{l}\mathrm{CO}_{2} \\
\text { emission } \\
\text { Costs }\end{array}$ & 0.33 & 0.24 & 0.43 & 1.00 \\
\hline
\end{tabular}

Table 23 Weight matrix (Validi et al. 2014a, b, 2015; Validi 2014)

Table 24 Limits of the attributes (Validi et al. 2014a, b, 2015; Validi 2014)

\begin{tabular}{lll}
\hline Attributes & \multicolumn{2}{l}{ Limits of $\mathrm{CO}_{2}$ emission and cost } \\
\cline { 2 - 3 } & Min & Max \\
\hline $\mathrm{CO}_{2}$ emission $(\mathrm{kg})$ & 2 & 215 \\
Costs $(€)$ & 2 & 150 \\
\hline
\end{tabular}

\section{References}

Aksen, D., \& Altinkemer, K. (2008). A location-routing problem for the conversion to the "click-and-mortar" retailing: The static case. European Journal of Operational Research, 186(2), 554-575.

Albareda-Sambola, M., Diaz, J. A., \& Fernández, E. (2005). A compact model and tight bounds for a combined location-routing problem. Computers \& Operations Research, 32(3), 407-428.

Albareda-Sambola, M., Fernández, E., \& Laporte, G. (2007). Heuristic and lower bound for a stochastic location-routing problem. European Journal of Operational Research, 179(3), 940-955.

Alumur, S., \& Kara, B. Y. (2007). A new model for the hazardous waste location-routing problem. Computers \& Operations Research, 34(5), 1406-1423.

Ambrosino, D., \& Scutellà, M. G. (2005). Distribution network design: New problems and related models. European Journal of Operational Research, 165(3), 610-624.

Asgari, N., Rajabi, M., Jamshidi, M., Khatami, M., \& Farahani, R. Z. (2017). A memetic algorithm for a multiobjective obnoxious waste location-routing problem: A case study. Annals of Operations Research, 250, 279-308.

Belenguer, J.-M., Benavent, E., Prins, C., Prodhon, C., \& Calvo, R. W. (2011). A branch-and-cut method for the capacitated location-routing problem. Computers \& Operations Research, 38(6), 931-941.

Bell, J. E., \& McMullen, P. R. (2004). Ant colony optimization techniques for the vehicle routing problem. Advanced Engineering Informatics, 18(1), 41-48.

Berger, R. T., Coullard, C. R., \& Daskin, M. S. (2007). Location-routing problems with distance constraints. Transportation Science, 41(1), 29-43.

Bin, Y., Zhong-Zhen, Y., \& Baozhen, Y. (2009). An improved ant colony optimization for vehicle routing problem. European Journal of Operational Research, 196(1), 171-176.

Brandenburg, M., \& Rebs, T. (2015). Sustainable supply chain management: A modeling perspective. Annals of Operations Research, 229, 213-252.

Bräysy, O., Porkka, P. P., Dullaert, W., Repoussis, P. P., \& Tarantilis, C. D. (2009). A well-scalable metaheuristic for the fleet size and mix vehicle routing problem with time windows. Expert Systems with Applications, 36(4), 8460-8475.

Bruns, A., Klose, A., \& Stähly, P. (2000). Restructuring of Swiss parcel delivery services. OR Spektrum, 22(2), 285-302. 
Caballero, R., González, M., Guerrero, F. M., Molina, J., \& Paralera, C. (2007). Solving a multiobjective location routing problem with a metaheuristic based on tabu search: Application to a real case in Andalusia. European Journal of Operational Research, 177(3), 1751-1763.

Cappanera, P., Gallo, G., \& Maffioli, F. (2004). Discrete facility location and routing of obnoxious activities. Discrete Applied Mathematics, 133(1-3), 3-28.

Chan, Y., Carter, W. B., \& Burnes, M. D. (2001). A multiple-depot, multiple-vehicle, location-routing problem with stochastically processed demands. Computers and Operations Research, 28(8), 803-826.

Chang, T.-S., Nozick, L. K., \& Turnquist, M. A. (2005). Multiobjective path finding in stochastic dynamic networks, with application to routing hazardous materials shipments. Transportation Science, 39(3), 383-399.

Chiang, W. C., \& Russell, R. A. (2004). Integrating purchasing and routing in a propane gas supply chain. European Journal of Operational Research, 154(3), 710-729.

Dekker, R., Bloemhof, J., \& Mallidis, I. (2012). Operations Research for green logistics-An overview of aspects, issues, contributions and challenges. European Journal of Operational Research, 219(3), 671-679.

Demir, E., Bektaş, T., \& Laporte, G. (2014). A review of recent research on green road freight transportation. European Journal of Operational Research, 237(3), 775-793.

Department for Environment, Food and Rural Affairs. (2008). Guidelines to Defra's GHG conversion factors: methodology paper for transport emission factors. London, UK.

Department of Energy \& Climate Change, UK. (2010). Monitoring and understanding $\mathrm{CO}_{2}$ emissions from road freight operations.

Derbel, H., Jarboui, B., Chabchoub, H., Hanafi, S., \& Mladenovic, N. (2011). A variable neighborhood search for the capacitated location-routing problem. In Proceedings of the 4th international conference on logistics, 31 May-3 June 2011, Hammamet, Tunisia, pp. 514-519.

Devika, K., Jafarian, A., \& Nourbakhsh, V. (2014). Designing a sustainable closed-loop supply chain network based on triple bottom line approach: A comparison of metaheuristics hybridization techniques. European Journal of Operational Research, 235(3), 594-615.

Diabat, A., \& Simchi-Levi, D. (2009). A carbon-capped supply chain network problem. In Proceedings of the IEEE international conference on industrial engineering and engineering management, 8-11 Dec. 2009, Hong Kong, pp. 523-527.

Drexl, M., \& Schneider, M. (2015). A survey of variants and extensions of the location-routing problem. European Journal of Operational Research, 241(2), 283-308.

Du, S., Hu, L., \& Wang, L. (2017). Low-carbon supply policies and supply chain performance with carbon concerned demand. Annals of Operations Research, 255, 569-590.

Duhamel, C., Lacomme, P., Prins, C., \& Prodhon, C. (2010). A GRASP $\times$ ELS approach for the capacitated location-routing problem. Computers \& Operations Research, 37(11), 1912-1923.

Erdoğan, S., \& Miller-Hooks, E. (2012). A green vehicle routing problem. Transportation Research Part E: Logistics and Transportation Review, 48(1), 100-114.

Eskandarpour, M., Dejax, P., Miemczyk, J., \& Péton, O. (2015). Sustainable supply chain network design: An optimization-oriented review. Omega, 54, 11-32.

Gendreau, M., Hertz, A., \& Laporte, G. (1994). A tabu search heuristic for the vehicle routing problem. Management Science, 40(10), 1276-1290.

Ghiani, G., \& Laporte, G. (1999). Eulerian location problems. Networks, 34(4), 291-302.

Ghodsi, R., \& Amiri, A. S. (2010). A variable neighborhood search algorithm for continuous location routing problem with pickup and delivery. In Proceedings of the fourth Asia international conference on mathematical/analytical modelling and computer simulation, 26-28 May, Kota Kinabalu, Malaysia, pp. 199-203.

Golden, B. L., \& Skiscim, C. C. (1986). Using simulated annealing to solve routing and location problems. Naval Research Logistics Quarterly, 33(2), 261-279.

Govindan, K., Jafarian, A., Khodaverdi, R., \& Devika, K. (2014). Two-echelon multiple-vehicle location-routing problem with time windows for optimization of sustainable supply chain network of perishable food. International Journal of Production Economics, 152, 9-28.

Gunnarsson, H., Rönnqvist, M., \& Carlsson, D. (2006). A combined terminal location and ship routing problem. Journal of the Operational Research Society, 57(8), 928-938.

Hwang, H.-S. (2002). Design of supply-chain logistics system considering service level. Computers \& Industrial Engineering, 43(1-2), 283-297.

Hwang, C. L., \& Yoon, K. (1981). Multiple attribute decision making. Lecture notes in economics and mathematical systems, Vol. 186, Berlin: Springer.

Ilbery, B., \& Maye, D. (2005). Food supply chains and sustainability: evidence from specialist food producers in the Scottish/English borders. Land Use Policy, 22(4), 331-344. 
Jacobsen, S. K., \& Madsen, O. B. G. (1980). A comparative study of heuristics for a two-level routing-location problem. European Journal of Operational Research, 5(6), 378-387.

Jin, L., Zhu, Y., Shen, H., \& Ku, T. (2010). A hybrid genetic algorithm for two-layer location-routing problem. In 4th International conference on new trends in information science and service science, 11-13 May, Gyeongju, South Korea, pp. 642-645.

Karaoglan, I., \& Altiparmak, F. (2010). A hybrid genetic algorithm for the location-routing problem with simultaneous pickup and delivery. In Proceedings of the 40th international conference on computers and industrial engineering, 25-28 July 2010, Awaji, Japan, pp. 1-6.

Karaoglan, I., Altiparmak, F., Kara, I., \& Dengiz, B. (2011). A branch and cut algorithm for the locationrouting problem with simultaneous pickup and delivery. European Journal of Operational Research, 211(2), 318-332.

Karaoglan, I., Altiparmak, F., Kara, I., \& Dengiz, B. (2012). The location-routing problem with simultaneous pickup and delivery: Formulations and a heuristic approach. Omega, 40(4), 465-477.

Kulcar, T. (1996). Optimizing solid waste collection in Brussels. European Journal of Operational Research, 90(1), 71-77.

Kumar, S., Teichman, S., \& Timpernagel, T. (2012). A green supply chain is a requirement for profitability. International Journal of Production Research, 50(5), 1278-1296.

Labbé, M., \& Laporte, G. (1986). Maximizing user convenience and postal service efficiency in post box location. Belgian Journal of Operational Research, Statistics and Computer Science, 26, 21-35.

Laporte, G., Louveaux, F., \& Mercure, H. (1989). Models and exact solutions for a class of stochastic locationrouting problems. European Journal of Operational Research, 39(1), 71-78.

Laporte, G., Norbert, Y., \& Taillefer, S. (1988). Solving a family of multi-depot vehicle routing and locationrouting problems. Transportation Science, 22(3), 161-172.

Lin, C. K. Y., Chow, C. K., \& Chen, A. (2002). A location-routing-loading problem for bill delivery services. Computers \& Industrial Engineering, 43(1-2), 5-25.

Lin, C. K. Y., \& Kwok, R. C. W. (2006). Multi-objective metaheuristics for a location-routing problem with multiple use of vehicles on real data and simulated data. European Journal of Operational Research, 175(3), 1833-1849.

Liu, H., Wang, W., \& Zhang, Q. (2012). Multi-objective location-routing problem of reverse logistics based on GRA with entropy weight. Grey Systems: Theory and Application, 2(2), 249-258.

Lopes, R. B., Barreto, S., Ferreira, C., \& Santos, B. S. (2008). A decision-support tool for a capacitated location-routing problem. Decision Support Systems, 46(1), 366-375.

Madsen, O. B. G. (1983). Methods for solving combined two level location routing problems of realistic dimension. European Journal of Operational Research, 12(3), 295-301.

Mantel, R. J., \& Fontein, M. (1993). A practical solution to a newspaper distribution problem. International Journal of Production Economics, 30-31, 591-599.

Marinakis, Y., \& Marinaki, M. (2008). A bilevel genetic algorithm for a real life location routing problem. International Journal of Logistics: Research and Applications, 11(1), 49-65.

Marinakis, Y., Marinaki, M., \& Matsatsinis, N. (2008). Honey bees mating optimization for the location routing problem. In Proceedings of the IEEE international engineering management conference, 28-30 June, Estoril, Portugal, pp. 1-5.

McKinnon, A., Browne, M., Whiteing, A., \& Piecyk, M. (Eds.). (2015). Green logistics: Improving the environmental sustainability of logistics. London: Kogan Page.

Melechovský, J., Prins, C., \& Calvo, R. W. (2005). A metaheuristic to solve a location-routing problem with non-linear costs. Journal of Heuristics, 11(5-6), 375-391.

Murty, K. G., \& Djang, P. A. (1999). The U.S. army national guard's mobile training simulators location and routing problem. Operations Research, 47(2), 175-182.

Nagy, G., \& Salhi, S. (2007). Location-routing: Issues, models and methods. European Journal of Operational Research, 177(2), 649-672.

Nguyen, V.-P., Prins, C., \& Prodhon, C. (2012). Solving the two-echelon location routing problem by a GRASP reinforced by a learning process and path relinking. European Journal of Operational Research, 216(1), $113-126$.

Nylund, N.-O., \& Erkkilä, K. (2005). Heavy-duty truck emissions and fuel consumption simulating real-world driving laboratory conditions. Presentation on behalf of VTT Technical Research Centre of Finland in the 2005 Diesel Engine Emissions Reduction (DEER) Conference, 21-25 Aug 2005, Chicago, Illinois, USA.

Or, I., \& Pierskalla, W. P. (1979). A transportation location-allocation model for regional blood banking. AIIE Transactions, 11(2), 86-94.

Perl, J., \& Daskin, M. S. (1984). A unified warehouse location-routing methodology. Journal of Business Logistics, 5(1), 92-111. 
Perl, J., \& Daskin, M. S. (1985). A warehouse location-routing problem. Transportation Research Part B: Methodological, 19(5), 381-396.

Prins, C., Labadi, N., \& Reghioui, M. (2009). Tour splitting algorithms for vehicle routing problems. International Journal of Production Research, 47(2), 507-535.

Prins, C., Prodhon, C., \& Calvo, R. W. (2006a). Solving the capacitated location-routing problem by a grasp complemented by a learning process and a path relinking. 4OR: A Quarterly Journal of Operations Research, 4(3), 221-238.

Prins, C., Prodhon, C., \& Calvo, R. W. (2006b). A memetic algorithm with population management (MAIPM) for the capacitated location-routing problem. Lecture Notes in Computer Science, 3906, 183-194.

Prins, C., Prodhon, C., Ruiz, A., Soriano, P., \& Calvo, R. W. (2007). Solving the capacitated location-routing problem by a cooperative Lagrangean relaxation-granular Tabu Search heuristic. Transportation Science, 41(4), 470-483.

Prodhon, C., \& Prins, C. (2014). A survey of recent research on location-routing problems. European Journal of Operational Research, 238(1), 1-17.

Przybylski, A., Gandibleux, X., \& Ehrgott, M. (2008). Two phase algorithms for the bi-objective assignment problem. European Journal of Operational Research, 185(2), 509-533.

Rath, S., \& Gutjahr, W. J. (2014). A math-heuristic for the warehouse location-routing problem in disaster relief. Computers \& Operations Research, 42, 25-39.

Rayat, F., Musavi, M. M., \& Bozorgi-Amiri, A. (2017). Bi-objective reliable location-inventory-routing problem with partial backordering under disruption risks: A modified AMOSA approach. Applied Soft Computing, 59, 622-643.

Rezaee, A., Dehghanian, F., Fahimnia, B., \& Beamon, B. (2017). Green supply chain network design with stochastic demand and carbon price. Annals of Operations Research, 250, 463-485.

Russell, R., Chiang, W. C., \& Zepeda, D. (2008). Integrating multi-product production and distribution in newspaper logistics. Computers \& Operations Research, 35(5), 1576-1588.

Saaty, T. L. (1994). How to make a decision: The analytic hierarchy process. Interfaces, 24(6), 19-43.

Sbihi, A., \& Eglese, R. W. (2010). Combinatorial optimization and green logistics. Annals of Operations Research, 175, 159-175.

Semet, F. (1995). A two-phase algorithm for partial accessibility constrained vehicle routing problem. Annals of Operations Research, 61(1), 45-65.

Seuring, S., \& Müller, M. (2008). From a literature review to a conceptual framework for sustainable supply chain management. Journal of Cleaner Production, 16(15), 1699-1710.

Sheu, J.-B., \& Li, F. (2014). Market competition and greening transportation of airlines under the emission trading scheme: A case of duopoly market. Transportation Science, 48(4), 684-694.

Srivastava, S. K. (2007). Green supply chain management: A state-of-the-art literature review. International Journal of Management Reviews, 9(1), 53-80.

Stenger, A., Schneider, M., Schwind, M., \& Vigo, D. (2012). Location routing for small package shippers with subcontracting options. International Journal of Production Economics, 140(2), 702-712.

Stowers, C. L., \& Palekar, U. S. (1993). Location models with routing considerations for a single obnoxious facility. Transportation Science, 27(4), 350-362.

Ting, C.-J., \& Chen, C.-H. (2013). A multiple ant colony optimization algorithm for the capacitated location routing problem. International Journal of Production Economics, 141(1), 34-44.

Toro, E. M., Franco, J. F., Echeverri, M. G., \& Guimarães, F. G. (2017). A multi-objective model for the green capacitated location-routing problem considering environmental impact. Computers \& Industrial Engineering, 110, 114-125.

Tuzun, D., \& Burke, L. I. (1999). A two-phase Tabu Search approach to the location routing problem. European Journal of Operational Research, 116(1), 87-99.

United Nations Treaty Collection. Paris Agreement. https://treaties.un.org/pages/ViewDetails.aspx?src= TREATY\&mtdsg_no=XXVII-7-d\&chapter=27\&clang=_en. Accessed December 24, 2017.

Validi S. (2014). Low carbon multi-objective location-routing in supply chain network design. Unpublished. $\mathrm{PhD}$ thesis, Dublin, Ireland: Dublin City University Business School.

Validi, S., Bhattacharya, A., \& Byrne, P. J. (2012). Greening the Irish food market supply-chain through minimal carbon emission: an integrated multi-objective location-routing approach. In: T. Baines, B. Clegg, \& D. Harrison (Eds.), Proceedings of the 10th international conference on manufacturing research, 11-13th September, Birmingham, UK (Vol. 2, pp. 805-810).

Validi, S., Bhattacharya, A., \& Byrne, P. J. (2014a). A case analysis of a sustainable food supply chain distribution system-A multi-objective approach. International Journal of Production Economics, 152, 71-87. 
Validi, S., Bhattacharya, A., \& Byrne, P. J. (2014b). Integrated low-carbon distribution system for the demand side of a product distribution supply chain: A DoE-guided MOPSO optimiser-based solution approach. International Journal of Production Research, 52(10), 3074-3096.

Validi, S., Bhattacharya, A., \& Byrne, P. J. (2015). A solution method for a two-layer sustainable supply chain distribution model. Computers \& Operations Research, 54, 204-217.

Vega-Mejía, C. A., Montoya-Torres, J. R., \& Islam, S. M. N. (2017). Consideration of triple bottom line objectives for sustainability in the optimization of vehicle routing and loading operations: A systematic literature review. Annals of Operations Research. https://doi.org/10.1007/s10479-017-2723-9.

Vidović, M., Ratković, B., Bjelić, N., \& Popović, D. (2016). A two-echelon location-routing model for designing recycling logistics networks with profit: MILP and heuristic approach. Expert Systems with Applications, 51, 34-48.

Wang, F., Lai, X., \& Shi, N. (2011). A multi-objective optimization for green supply chain network design. Decision Support Systems, 51(2), 262-269.

Wang, X., Sun, X., \& Fang, Y. (2005). A two-phase hybrid heuristic search approach to the location-routing problem. IEEE International Conference on Systems, Man and Cybernetics, 4, 3338-3343.

Wasner, M., \& Zäpfel, G. (2004). An integrated multi-depot hub-location vehicle routing model for network planning of parcel service. International Journal of Production Economics, 90(3), 403-419.

Watson-Gandy, C. D. T., \& Dohrn, P. J. (1973). Depot location with van salesmen-A practical approach. Omega, 1(3), 321-329.

Wu, H.-J., \& Dunn, S. C. (1995). Environmentally responsible logistics systems. International Journal of Physical Distribution \& Logistics Management, 25(2), 20-38.

Wu, T.-H., Low, C., \& Bai, J.-W. (2002). Heuristic solutions to multi-depot location-routing problems. Computers \& Operations Research, 29(10), 1393-1415.

Wu, X., Nie, L., \& Xu, M. (2017). Designing an integrated distribution system for catering services for highspeed railways: A three-echelon location routing model with tight time windows and time deadlines. Transportation Research Part C, 74, 212-244.

Yang, J., \& Zhuang, Y. (2010). An improved ant colony optimization algorithm for solving a complex combinatorial optimization problem. Applied Soft Computing, 10(2), 653-660.

Yang, P., \& Zi-Xia, C. (2009). Two-phase particle swarm optimization for multi-depot location-routing problem. In Proceedings of international conference on new trends in information and service science. Beijing, 30 June-2 July 2009, pp. 240-245.

Yao, B., Yu, B., Hu, P., Gao, J., \& Zhang, M. (2016). An improved particle swarm optimization for carton heterogeneous vehicle routing problem with a collection depot. Annals of Operations Research, 242, 303-320.

Yu, V. F., Lin, S.-W., Lee, W., \& Ting, C.-J. (2010). A simulated annealing heuristic for the capacitated location routing problem. Computers \& Industrial Engineering, 58(2), 288-299.

Yu, B., \& Yang, Z. Z. (2011). An ant colony optimization model: The periodic vehicle routing problem with time windows. Transportation Research Part E: Logistics and Transportation Review, 47(2), 166-181.

Zhang, S., Gajpal, Y., \& Appadoo, S. S. (2017). A meta-heuristic for capacitated green vehicle routing problem. Annals of Operations Research. https://doi.org/10.1007/s10479-017-2567-3.

Zhang, Y., \& Zhao, J. (2011). Modeling and solution of the hazardous waste location-routing problem under uncertain conditions. In Third international conference on transportation engineering, Chengdu, China, 23-25 July, pp. 2922-2927.

Zhou, J., \& Liu, B. (2007). Modeling capacitated location-allocation problem with fuzzy demands. Computers \& Industrial Engineering, 53(3), 454-468.

Zhu, Q., Sarkis, J., \& Lai, K.-H. (2008). Green supply chain management implications for closing the loop. Transportation Research Part E: Logistics and Transportation Review, 44(1), 1-18. 